\title{
Does a ban on trans fats improve public health: synthetic control evidence from Denmark
}

\author{
Rok Spruk* (D) and Mitja Kovac
}

\begin{abstract}
We examine the impact of the trans fat ban on a variety of public health outcomes. To this end, we consider a de facto trans fat ban that was introduced by Denmark in 2001. Using the synthetic control method, parallel trends between Denmark and countries in a control group in the years prior to the ban are used to construct a "synthetic Denmark" without any such trans fat ban. Our synthetic control estimates suggest the ban led to substantial improvements in public health. Following the ban, cardiovascular mortality dropped considerably, while the trends of adolescent and child obesity came to a halt and decreased significantly compared to the synthetic control group. Our findings provide new insights into the benefits for public health arising from the banning of trans fats.
\end{abstract}

\section{Introduction}

The consumption of trans-saturated fats is long recognized as a great public health concern. In particular, cardiovascular disease is a major cause of death in most OECD countries. The consumption of trans fat acids (TFAs), chiefly present in partially hydrogenated oils, is clearly associated with elevated LDL ("bad") cholesterol levels and a drop in HDL ("good") cholesterol levels, which negatively impacts the heart and metabolism in general and is also associated with rising obesity rates. Many studies over the years point to the adverse impact of trans fats (Baer et al. 2004, Mozaffarian et al. 2006, Teegala et al. 2009, Brouwer et al. 2013). Yet, the question remains: to what extent can a policy intervention aimed at limiting/removing trans fats from the food supply improve public health outcomes?

Ever since Proctor and Gamble introduced Crisco in 1911, TFAs have seen widespread use due to their commercially favorable properties like long shelf life and stability while deep frying. TFAs were incorporated into various processed foods such as snacks, biscuits, deepfried foods, prepackaged foods, margarines, and crackers. Created by adding hydrogens to vegetable oils, partially

\footnotetext{
* Correspondence: rok.spruk@ef.uni-lj.si

School of Economics and Business, University of Ljubljana, Kardeljeva ploscad 17, 1000 Ljubljana, Slovenia
}

hydrogenated oils serve as a primary dietary source of TFAs. In the early 1990s, epidemiological studies (Koletzko 1992, Ascherio et al. 1994) found that higher plasma concentration of LDL cholesterol and low concentration of HDL cholesterol are reliable markers of cardiovascular risk. The general thrust of these studies is that even small rises in TFA consumption can increase LDL cholesterol substantially by about $+0.04 \mathrm{mmol} / \mathrm{L}$. Beyond doubt, trans fats increase the risk of cardiovascular disease mainly by disturbing the balance between high-density (HDL) and low-density (LDL) cholesterol. Hence, trans fat consumption poses a key public health risk by way of obesity rates and cardiovascular diseases (Stender et al. 2006, Oh et al. 2005, Uauy et al. 2009, Missmer et al. 2010).

The economic benefits of lowering the prevalence of TFAs are substantial. Allen et al. (2015) estimate that a $1 \%$ reduction in TFA energy intake in England and Wales would generate some 3900 fewer deaths, 10,000 fewer hospital admissions, and see 37,000 life years being gained by 2030 while substantially shrinking health inequalities between the most affluent and most deprived income quantiles, whereas no such effects were found for policies relying on industry to voluntarily reformulate its products. The economic effects of growing obesity rates and prevalence of overweight in response to trans 
fats consumption are both persistent and significant (Astrup et al. 2008). Cawley (2004) suggests that a 2standard deviation increase in body weight is associated with a $9 \%$ drop in wages, namely, the equivalent of 1.5 years' lost education and 3 years' foregone work experience. Using restricted data from the Medical Expenditure Panel Survey in the USA and considering genetic weight variation, Cawley and Meyerhoefer (2012) estimate that obesity raises annual medical inflationadjusted costs by US $\$ 2471$ and brings several negative externalities (Kortt et al. 1998, Finkelstein et al. 2009, Trasande et al. 2009, Thorpe et al. 2004).

The widespread use of trans fats particularly harms the physical health of children and adolescents. Several channels that explain the adverse effects of TFAs on children and adolescent health have been identified. First, food prices exhibit a clear downward between 1990 and 2017, which is associated with greater demand for food and higher intake of high-calorie food. For instance, the price of a bottle of Coca-Cola in the said period dropped 35\%, and the price of a McDonalds' "quarter-pounder" dropped by $5.5 \%$. The evidence suggests that food-price reductions account for 41 to $43 \%$ of the increase in young adults' body mass index (BMI) between 1981 and 1984, where children from lowincome families appear to be the most affected (Cawley 2010). On the other hand, vegetable prices rose by $17 \%$ in the 1997-2003 period, further explaining the increasing trend of obesity rates and prevalence of overweight (Powell 2009, Powell and Chaloupka 2009, Sturm and Datar 2005, Gelbach et al. 2007, Zheng and Zhen 2008, Auld and Powell 2009). Second, rising incomes are generally recognized as a factor in the growing obesity rates. The impact of income on obesity rates can operate in two directions. Higher income can induce a substitution effect and encourage consumers to substitute healthier but costlier options with cheaper energy-dense foods, mainly by growing demand for good health and an attractive appearance (Philipson 2001). Yet, rising income can encourage people to consume more calories and indulge in a sedentary lifestyle. The direction of the income effect is not empirically clear and varies substantially with age, year, sex, and race (Sobal and Stunkard 1989, Schmeiser 2009, Cawley et al. 2010). ${ }^{1}$

Several studies establish a link between maternal employment and childhood obesity (Anderson et al. 2003, Von Hinke Kessler Scholder 2008, Fertig et al. 2009). These studies suggest an increase in the mother's weekly work hours explains 11 to $34 \%$ of the rise in childhood obesity in families with a high socioeconomic status

\footnotetext{
${ }^{1}$ Wang and Zhang (2002) examine the relationship between income and childhood obesity by race and show that the negative correlation between income and obesity holds for white girls only.
}

between 1975 and 1994. The positive impact of the mother's weekly work hours on childhood obesity is not uniform, and holds for children whose mothers work full time and when the child is at least 7 years of age, but not when the child is either preschool age or aged 11, and not when mothers work part-time regardless of the child's age. The mechanism underlying maternal employment and childhood obesity appears to be straightforward. Full-time maternal employment is associated with less time spent cooking and more time spent watching TV and playing video games. This increases the probability the family will consume prepared foods, which are calorie-dense and contain high levels of TFAs (Cawley and Fiu 2012). Another potential mechanism explaining maternal employment's effect on childhood obesity is the choice of childcare arrangements since children in center-based care are more likely to be obese than children cared for by non-paternal relatives or even a nanny (Herbst and Tekin 2011). In addition, Philipson and Posner (2008) claim that technological advances in the mass preparation of food explain the rising obesity rates, while Cutler et al. (2003), Komlos et al. (2004), and Komlos and Baur (2004) highlight the importance of patience given that people seem willing to exchange their future health for the immediate gratification of their instant needs.

Obesity imposes considerable economic costs that tend to persist. Trasande et al. (2009) and Trasander and Chatterjee (2009) estimate the direct cost of childhood obesity in the USA at US\$14.1 billion. The effects of childhood obesity persist into adulthood. One third of preschool obese children and one-half of school-aged children become obese adults (Serdula et al. 1993). Finkelstein et al. (2009) believe the annual cost of treating obese adults in the USA is about US\$147 billion, whereas Thorpe et al. (2004) show that in the period $1987-2001$ the rise in obesity accounts for $27 \%$ of the rise in healthcare spending. The indirect economic costs of obesity are high. Apart from the employer-related cost, Cawley and Spiess (2008) show that childhood obesity in the age range 2 to 3 years results in delayed skill acquisition, holding important implications for human capital formation. Controlling for cognitive skills and education, childhood obesity predicts significantly lower wages in adulthood (Cawley 2004). Moreover, adult obesity in the USA leads to job market absenteeism, annually adding US\$14.3 billion to employer costs (Cawley et al. 2007).

This paper complements our earlier work (Kovac and Spruk 2019) on the impact of trans fat bans on public health in three noteworthy respects. First, we construct a counterfactual scenario by exploiting the parallel public health trends between affected and unaffected countries and build a trajectory of obesity rates and cardiovascular 
disease-related death rates in the hypothetical absence of the ban. Second, we add an extensive battery of covariates related to food demand structure, public health expenditure, consumer prices, physical geography, and intellectual aptitude to undertake a synthetic matching between Denmark and the rest of the world in the period before the implementation of the ban. By constructing a counterfactual scenario, we allow for the possibility of pre-ban trends in public health outcomes to the shape the trajectory of the public health outcomes over time had the ban never came into force which provides for an improved understanding of the effect size and significance associated with the ban. And third, this paper evaluates the impact of the ban on cardiovascular mortality and obesity rates and does not discuss the impact of non-ban trans fat policies compared to our earlier paper.

Several other papers are related to ours. First, Restrepo and Rieger (2016a) use annual mortality rates in a sample of OECD countries for the period 1990-2012 to estimate the effect of Denmark's trans fat ban on the cardiovascular (CVD) mortality rate. More specifically, they simulate the CVD mortality trajectory Denmark would have taken in the absence of passing a trans fat ban. Their results show that, 3 years after introducing the ban, the annual CVD-related mortality rate had fallen by 14.2 deaths per 100,000 people relative to the synthetic control group. Second, Restrepo and Rieger (2016b) examine the impact of the trans fats ban on CVD by considering the 2005 policy change made by the state of New York that prohibited artificial trans fats ingredients in food-service establishments. Their findings suggest the policy led to a $4.5 \%$ drop in CVD-related mortality, or roughly 13 fewer deaths per 100,000 inhabitants per year, which can be economically valued at some US $\$ 3.9$ million per 100,000 inhabitants annually. Using a panel containing more countries with a substantially larger set of covariates, we reevaluate the effects of Denmark's trans fat ban on the CVD mortality rate and estimate its impact on obesity rates and body weight. Our results confirm Restrepo and Rieger's (2016a) findings and suggest the trans fat ban is associated with a considerable slowdown in obesity trends, particularly for children and adolescents. By examining similar policy changes in countries other than Denmark, we do not find similar effects of such a ban on CVD-related mortality and obesity.

Our results imply that the ban on trans fats is associated with a reduced cardiovascular mortality rate of about 53 age-standardized deaths from 2001 to 2015 compared to the countries without such legislation in place. The reduction in the mortality rate is not immediate but tends to amplify in the long run. The effects of the ban on obesity rates are somewhat mixed. In particular, we find a relatively large reduction in adolescent obesity whereas the effects on child obesity rates are somewhat weaker. On the other hand, the effect on adult obesity rate cannot be plausibly distinguished from zero. The effect of the trans fats on cardiovascular mortality and obesity appears to be specific to Denmark since we do not find similar effects in other countries that subsequently passed a trans fat ban. A battery of placebo checks confirms our baseline results.

The rest of the paper is organized as follows. Section 2 describes the policy context of Denmark's trans fat ban in a comparative perspective. Section 3 discusses the identification strategy, while section 4 presents the data. Section 5 presents the results and robustness checks and section 6 concludes.

\section{Trans fats and public health: the policy context}

\subsection{Overview of trans fat policies}

The adverse effects of consuming trans fats raise several rationales for government intervention. The most obvious rationale for a policy response to tackle the impacts of trans fat consumption is to internalize the external costs stemming from trans fat consumption that are borne by third parties. Nevertheless, a ban is not the sole policy tool available to address the negative implications of trans fat consumption. Another popular policy measure to counter trans fat consumption is an obesity tax, which may be characterized as a form of Pigouvian taxation to discourage unhealthy diets and partially offset the economic costs of obesity ${ }^{2}$ or to subsidize healthy activities. An alternative approach for discouraging trans fat consumption is to rely on voluntary agreements and information-disclosure requirements such as calorie labeling (Restrepo 2017). The idea behind this idea is that providing more information to consumers may affect their choices in socially desirable ways. Elbel et al. (2009) examine the effects of calorie labeling on food choices in fast-food restaurants following a policy change in food labeling legislation introduced on June 8, 2008. Their results show the introduction of mandatory labeling was not associated with any change in terms of the number of calories purchased (Vadiveloo et al. 2011, Elbel et al. 2011, Cantor et al. 2015). On the other hand, Variyam and Cawley (2006) estimate the impact of labeling on

\footnotetext{
${ }^{2}$ In 2008, Japan passed the act known as the "metabo" law (Onishi 2008). The law included the measurement of waist sizes in an attempt to overcome increasing obesity rates. Waist-size measurement included individuals aged between 40 and 75 and was administered by employers and local government which had to ensure there was a minimum of 65 percent participation. The law aimed to decrease Japan's obesity rates by 25 percent. Other countries passing laws taxing unhealthy food include Denmark, which implemented a "fat tax" in 2011 and repealed it the subsequent year, and India, where the state of Kerala introduced 14.5 percent "fat tax" on burgers, pizzas, doughnuts, tacos, and other junk food served in branded restaurants.
} 
body weight by considering the Nutrition Labeling and Education Act (NLEA) and applying difference-indifference methods. They find that implementation of the new label was associated with decreased body weight and prevalence of obesity, but only among non-Hispanic white women.

The general thrust of trans fat policies is to protect consumers who are acting irrationally as their food choices may lead to problems associated with time inconsistency and addiction. Children and adolescents are particularly vulnerable to becoming addicted to food rich in trans fats. An alternative approach to tackle the bad effects of trans fats on public health might be to ban food companies from advertising fast food and sugary drinks to children and adolescents (Dhar and Baylis 2011). Chou et al. (2008) estimate the impact of a ban on fast-food TV advertisements of fast-food restaurants on child obesity rates. Their results suggest a ban on television fast-food advertising would reduce the share of overweight children and adolescents substantially (Livingstone 2006, Gostin 2007, Hawkes 2007, Harris et al. 2009).

\subsection{Trans fats ban: the case of Denmark}

In 2003, Denmark became the first country to introduce legislation banning artificial trans fats (Bech-Larsen and Aschemann-Wenzel 2012). The law $^{3}$ mandates $2 \mathrm{~g}$ of TFAs per $100 \mathrm{~g}$ as the maximum content of artificial trans fats in oil and fats. ${ }^{4}$ The idea of banning trans fats in Denmark originates in a 1993 Lancet article discussing the harmful effect of TFAs on coronary heart disease (Willett et al. 1993) which received widespread media attention. In response to the article, the Danish Nutrition Council (DNC) called for a meeting to discuss the new evidence. In 1994, the DNC and the Association of Danish Margarine Producers (MIFU) signed a voluntary agreement to reduce and partially eliminate TFAs from butter and margarine products. Subsequently, major Danish retailers followed the agreement and changed their practice. Yet the initiative did not hinge on the Danish Dairy Board because a sizeable proportion of TFAs had been prevalent in dairy products. Following the agreement, the MIFU moved to invest in technologies able to eliminate or significantly reduce TFAs in their products since the existing TFA technology was expensive and created problems such as "mouth feel" and melting point for certain industrial consumers like bakeries.

\footnotetext{
${ }^{3}$ Danish Veterinary and Food Administration, Ministry of Environment and Food https://www.foedevarestyrelsen.dk/english/Food/Trans\%2 Ofatty\%20acids/Pages/default.aspx

${ }^{4}$ Studies suggest that, before 2001, it was possible to consume $30 \mathrm{~g}$ of artificial trans fat by eating two to three popular food products (i.e., biscuits, popcorn, chicken nuggets, French fries). In 2005, the proportion of trans fats fell to $1 \mathrm{~g}$, respectively (Stender et al. 2006).
}

A turning point in the Danish government's policy stance on TFAs came with publication of the EU White Paper on food safety in 2000. Before 2001, no action had been taken to tackle TFAs in the food supply. In 2001, a large majority of food producers in Denmark was complying with the $2 \%$ TFA limit, implying that 2001 may be regarded as the de facto year of the TFA policy change. In 2001, Minister for Food Ritt Bjeregaard requested the DNC provide a review of health risks associated with TFA consumption. Even though TFA in most margarines had already been reduced to $<1 \%$, TFAs were in widespread use and found in processed foods like cakes, biscuits, crisps, and fast food. Most of these foods were imported and entailed their own marketing systems. After reviewing the evidence, the DNC called for mandatory TFA standards to apply to the entire food supply while also advocating the prohibition of TFAs, making it clear the ban would soon come into effect. After a change in the government administration in 2002, incoming Minister for Food, Mariann Fischer Boel stressed the need to regulate TFAs in the light of related significant health risks. The new government then extended the voluntary agreement from 2001, covering oil and fat produced by Danish companies, to all food produced and marketed in Denmark. On January 1, 2004, the ban came into force.

In 2004, the EU Commission claimed the TFA ban meant Denmark was in breach of Articles 28 and 30 of the EC Treaty on the free movement of goods and sought to prosecute the case before the European Court of Justice. In 2006, the EU suggested a 10\% TFA limit whereas the European Consumer Organisation supported the Danish policy and urged the EU Commission to not interfere with the Danish regulation but to move towards introducing a similar regulation across the EU. In 2007, the EU Commission accepted the Danish standards and dropped the case at the ECJ, yet without advocating any EU-wide regulation of TFAs. Similar bans had in the meantime been passed by several other countries, still with notable differences from the Danish TFA legislation. In 2008, Switzerland introduced a 2\% TFA limit that applied solely to vegetable oils. ${ }^{5}$ In 2009 , Austria imposed a similar 2\% TFA limit, which only applied if the fat content represented $20 \%$ of the total weight of a food product. ${ }^{6}$ In 2011, Iceland introduced

\footnotetext{
${ }^{5}$ Verordnung des EDI über Speiseöl, Speisefett und daraus hergestellte Erzeugnisse. Die Bundesbehörden der schweizerischen Eidgenossenschaft. Available at https://www.admin.ch/opc/de/ classified-compilation/20050165/index.html\#fn6

${ }^{6}$ Verordnung des Bundesministers für Gesundheit über den Gehalt an trans-Fettsäuren in Lebensmitteln. Bundesgesetzblatt für die Republik Österreich. Available at https://www.ris.bka.gv.at/GeltendeFassung. wxe? Abfrage $=$ Bundesnormen\&Gesetzesnummer $=20006420 \&$ ShowPrintPreview $=$ True
} 
the same 2\% TFA limit ${ }^{7}$ as Denmark. In 2014, Norway introduced a $2 \%$ TFA limit, but, unlike the Danish legislation, several products specifically regulated by other legislation were exempted from the ban. ${ }^{8}$ In the same year, Hungary enacted a $2 \%$ TFA limit almost identical to the Austrian version of the ban from 2009. ${ }^{9}$ In the USA, several states and cities, including New York City in $2005^{10}$ and the state of California in $2008,^{11}$ introduced partial TFA bans but only in food-service establishments. Most other industrialized countries such as Germany $^{12}$, France $^{13}$, and the UK ${ }^{14}$ tend to favor the use of voluntary agreements regarding the presence of TFAs in the food supply.

\section{Identification strategy}

Introduction of the ban may be viewed as a policy intervention occurring at the aggregate level. Comparative case studies are required to understand such a setup entailing the introduction of the TFA ban that potentially impacts public health outcomes. Outcomes in the countries under examination can be compared with control-sample countries in which there is no similar

\footnotetext{
${ }^{6}$ Verordnung des Bundesministers für Gesundheit über den Gehalt an trans-Fettsäuren in Lebensmitteln. Bundesgesetzblatt für die Republik Österreich. Available at https://www.ris.bka.gv.at/GeltendeFassung. wxe :Abfrage $=$ Bundesnormen $\&$ Gesetzesnummer $=20006420 \&$ Show PrintPreview $=$ True

${ }^{7}$ Regulation no. 79/2010 establishing maximum levels of trans fatty acids in foods. Ministry of Industries and Innovation. Available at https://www.stjornarradid.is/raduneyti/atvinnuvega-ognyskopunarraduneytid/

${ }^{8}$ Forskrift om transfettsyrer i næringsmilder. Helse- og omsorgsdeparementet. Available at https://lovdata.no/dokument/SF/ forskrift/2014-01-16-34

${ }^{9}$ Országos Élelmezés- és Táplálkozástudományi Intézet. az élelmiszerekben lévo transz-zsírsavakmegengedheto legnagyobb mennyiségérol, a transz-zsírsav tartalmú élelmiszerek forgalmazásának feltételeirol és hatósági ellenorzésérol, valamint a lakosság transz-zsírsav bevitelének nyomon követésére vonatkozó szabályokról. Available at http://portal.nebih.gov.hu/-/tajekoztato-a-transz-zsirsavakrol

${ }^{10}$ Department of Health and Mental Hygiene, Board of Health, Notice of Adoption of an Amendment (\$81.01) to Article 81 of the New York City Health Code 1. Available at http://rules.cityofnewyork.us/content/ article-81-food-preparation-and-food-service-establishments

${ }^{11}$ California Health and Safety Code $(\$ 114335)$. Available at https:// codes.findlaw.com/ca/health-and-safety-code/hsc-sect-114335.html

${ }^{12}$ Leitlinien zur Minimierung von Trans-Fettsäuren in Lebensmitteln. Gemeinsame Initiative der deutschenLebensmittelwirtschaft und des Bundesministeriums für Ernährung, Landwirtschaft undVerbraucherschutz. Available at https://www.bll.de/de/lebensmittel/ernaehrung/fett/tfa-trans-fettsaeuren

${ }^{13}$ Les chartes d'engagements volontaires de progrès nutritionnel. Ministère des Affaires sociales, de laSanté et des Droits des femmes. Available at http://solidarites-sante.gouv.fr/prevention-en-sante/ preserver-sa-sante/le-programme-nationalnutrition-sante/article/leschartes-d-engagements-volontaires-de-progres-nutritionnel

${ }^{14}$ Public Health Responsibility Deal to voluntarily remove artificial trans fats from all foods. Available at https://webarchive. nationalarchives.gov.uk/20111114230956/http://responsibilitydeal.dh. gov.uk/files/2011/09/PHRD_pledges_120911.pdf
}

policy intervention. Following Abadie and Gardeazabal (2003), Abadie et al. (2010, 2015), Klößner et al. (2018), Cavallo et al. (2013), Kleven et al. (2013), Billmeier and Nannicini (2013), Neumark et al. (2014), Acemoglu et al. (2016), and Gobillon and Magnac (2016), we construct a counterfactual scenario from a synthetic control group.

Our goal is to ascertain the public health outcomes in the affected countries had the TFA ban not taken place on a designated date. The key identifying assumption made is that the control countries' trends in health outcomes capture parallel trends in the affected countries prior to imposition of the ban, and provide a credible counterfactual for what the trends would otherwise have been in the quasi-treated countries absent any TFA ban. While a standard difference-in-difference analysis might unveil the effect of the TFA ban on average, we are interested in how the counterfactual scenario evolves in each year after the policy intervention which is why, in our view, the synthetic control method is a better choice for this purpose.

Let us observe $J+1$ countries over $t=1, \ldots T$ periods, with one country (i.e., Denmark) being treated and other countries $\{2, \ldots, J+1\}$ being unaffected by the ban. The ban occurs at time $T_{0}$ and is in effect for the full posttreatment period starting with $T_{0}+1$ where $1<T_{0}+1<$ $T$. At the designated time of the intervention, the ban affects only one country and leaves the other $J$ states unaffected. Our aim is to measure the ban's impact on the public health outcomes of Denmark as the treated country. Let the outcome for country $i$ at time $t$ in the absence of the ban be $y_{i, t}^{N}$, and let $y_{i, t}^{I}$ represent the outcome if the $i$-th country were exposed to the ban so that Denmark is represented as $i=1$. We assume the intervention has no impact on the outcome prior to the ban such that $y_{i, t}^{I}=y_{i, t}^{N}$ for $t<T_{0}+1$. For the intervention that takes place at time $T_{0}$, the ban's full effect is described as $\lambda_{i}=\left\{\lambda_{i, 1}, \lambda_{i, T_{0}}, \lambda_{i, T_{0}+1}, \ldots, \lambda_{i, T}\right\}$ which estimates the ban's effect over time, and captures the difference between the observed and counterfactual outcomes, which implies that $\lambda_{i}=y_{i, t}^{I}-y_{1, t}^{N}=y_{1, t}^{\text {Observed }_{-}}$ $y_{1, t}^{\text {Counterfactual }}$.

Given the policy context of the Danish ban described in section 2, we consider the ban's de facto introduction in 2001 rather than the time of introducing de jure legislation in 2003 by way of as a policy change because the ban had already been anticipated following the review of health risks commissioned from the DNC. Suppose that the outcomes follow a latent factor model:

$$
y_{j, t}^{N}=\delta_{t}+\theta_{t} \cdot Z_{j}+\gamma_{t} \cdot \mu_{j}+u_{j, t}
$$

where $\delta$ is the unobserved factor common to all countries, $Z_{j} \in \mathbb{R}^{r}$ is the vector of observed covariates 
unaffected by the ban, and $\theta$ is a vector of unobserved parameters, $\gamma_{t} \in \mathbb{R}^{F}$ is a vector of common unobserved factors, and $\mu_{j} \in \mathbb{R}^{F}$ is a vector of unobserved factor loadings. Transitory shocks $u_{j, t}$ capture innovations' impacts on outcomes and we assume they have a zero mean. The latent factor model allows for heterogeneous responses to multiple unobserved factors $\left(\gamma_{t} \cdot \mu_{j}\right)$ and embeds time trends into the model. Using the latent factor model, our goal is to reweigh the control group so that the synthetic country matches $Z_{j}$ and some pre-ban $y_{j, t}$ of Denmark as the affected country. This implies that $\mu_{j}$ are matched between the treatment and control samples prior to the de facto policy intervention in 2001. Let $W=\left(w_{2}, \ldots, w_{J+1}\right)$ be a vector of weights with $w_{j} \geq 0 \forall j$, and let each value of $W$ represent a potential synthetic control unit. For a given $W$, the outcome for a synthetic control unit at time $t$ is:

$$
\begin{aligned}
& y_{W, t}=\sum_{j=2}^{J+1} w_{j} \cdot y_{j, t}=\delta_{t}+\theta_{t}\left(\sum_{j=2}^{J+1} w_{j} \cdot Z_{j}\right)+ \\
& \gamma_{t}\left(\sum_{j=2}^{J+1} w_{j} \cdot \mu_{j}\right)+\left(\sum_{j=2}^{J+1} w_{j} \cdot u_{j, t}\right)
\end{aligned}
$$

Since $\exists W^{\prime \prime}$ is such that the synthetic control unit matches the treated country in the entire pre-ban period, the synthetic control associated with $W^{*}$ replicates the missing counterfactual scenario and yields an approximately unbiased estimator of $\lambda_{1, t}$ given by

$$
\hat{\lambda}_{1, t}=y_{1, t}-\sum_{j=2}^{J+1} w_{j}^{*} \cdot y_{j, t}=y_{1, t}-y_{W^{*}, t}
$$

which corresponds to the difference between the observed outcome and the outcome of the synthetic control unit.

\section{Data}

\subsection{Outcomes}

We use public health data from Health at a Glance 2017 published by the OECD. ${ }^{15}$ We consider six validated, high-quality indicators: (1) cardiovascular disease (CVD) death rate, (2) childhood obesity rate, (3) adolescent obesity rate, (4) adult obesity rate, (5) fraction of overweight population, and (6) body mass index. Our sample comprises 38 OECD and non-OECD countries ${ }^{16}$ in a

\footnotetext{
${ }^{15}$ Detailed information about the cross-country health indicators and the associated methodology can be found at http://www.oecd.org/ health/health-systems/health-at-a-glance-19991312.htm

${ }^{16}$ Australia, Austria, Belgium, Brazil, Canada, Chile, Colombia, Costa Rica, Czech Republic, Denmark, Estonia, Finland, France, Germany, Greece, Hungary, Iceland, Ireland, Israel, Italy, Japan, Latvia, Lithuania, Mexico, Netherlands, New Zealand, Norway, Poland, Portugal, Russia, Slovakia, Slovenia, South Korea, Spain, Sweden, Switzerland, the UK, and the USA
}

strongly balanced panel for the period 1990-2016. The key outcome of interest is the CVD death rate. We compute the age-standardized number of deaths per 100,000 inhabitants from cardiovascular disease to make it comparable both across and within countries and eschew the biases inherent in using crude death rates which may be characterized by a skewed distribution of deaths. The data on obesity rates, fraction of overweight, and body mass index (BMI) come from the World Health Organization's Global Health Observatory. These indicators have been validated by numerous experts in the field. ${ }^{17}$

\subsection{Covariates}

\subsubsection{Past outcomes}

For each outcome, we use its past levels up until the de facto policy intervention in 2001 to predict the current outcome level. Specifically, we use the past outcome for the years 1990, 1995, and 2000. This allows us to capture the effects of the initial conditions, the pre-ban public health outcomes, as well as the level in-between.

\subsubsection{Food demand structure}

We use a large set of covariates related to the structure of food demand from the Economic Research Service of the U.S. Department of Agriculture (Seale et al. 2003). The covariates include price and income elasticities of demand for the following food categories: beverages and tobacco, bread and cereals, meat, fish, dairy products, oil and fat, fruits and vegetables, and other categories, which totals 16 covariates capturing the price and income elasticity of demand at the country level. Since including all indicators in the set of covariates separately may induce collinearity bias, we extract the most powerful latent components of food demand from the elasticity data using principal component analysis. Factor rotation yields two components with eigenvalues greater than 1 , which we retain. Specifically, the first component accounts for $88 \%$ of the common variance in the elasticity indicators while the second component accounts for $11 \%$ of total variance. The constructed principal components have a relatively high level of internal consistency as Cronbach (1952) alpha coefficient is 0.9 for the first component and 0.8 for the second components, respectively.

\subsubsection{Other covariates}

In addition, we consider several covariates associated with public health levels that are not directly influenced by the TFA ban as such. More specifically, such covariates include health expenditure as a log share of GDP (from World Development Indicators), blood pressure level (from the 2018 Global Burden of Disease dataset).

\footnotetext{
${ }^{17}$ Further information on the methodology behind this particular set of indicators can be found at http://www.who.int/gho/en/
} 
The macroeconomic covariates comprise the consumer price index and changes in that index and come from U.S. Department of Agriculture's Economic Research Service, and GDP per capita at constant prices adjusted for purchasing power parity (Feenstra et al. 2015). The geography covariates include latitude and longitude (from the CIA World Factbook), while demographic covariates comprise the share of age-dependent population, birth rate, and population growth rate (from World Development Indicators). To capture the confounding effects of human capital on public health, we use the level of IQ as measured by Lynn and Vanhanen (2006). Finally, food consumption covariates comprise the intake of fruit and vegetables, sugar, protein, fat, and calories. The consumption variables are expressed in $\mathrm{kg}$ per inhabitant while the caloric intake variable is denoted in kcal per inhabitant. Table 1 reports the key descriptive statistics for the covariates used in our synthetic control analysis.

\section{Results}

\subsection{Baseline effects of the ban}

Figure 1 presents the TFA ban's baseline effects on the CVD-related death rate, and obesity rates for various age cohorts. All dependent variables, except BMI, are denoted in the natural log. The synthetic control estimates are based on 31 covariates used to predict CVD death rates and other outcomes. Our results suggest the CVD death rate dropped substantially in response to the de facto TFA ban in 2001. In addition, the rising obesity rates came to a halt in response to the ban compared with those in the synthetic control group. In quantitative terms, the ban's impacts seem to materialize over the long run while the short-run effect is less certain. Prior to the ban, the CVD death rate of Denmark and its synthetic counterpart tended to move in tandem, while a clear structural break is indicated by the de facto ban in 2001. After 2001, Denmark's CVD death rate begins to drop slowly but persistently. By 2015, the observed CVD death rate in Denmark was 53 age-standardized deaths per 100,000 inhabitants. In contrast, the CVD death rate of the synthetic control group in 2015 stands at 83.09 age-standardized deaths per 100,000 inhabitants. This implies the de facto TFA ban in 2001 is associated with 30 fewer deaths per 100,000 inhabitants relative to the counterfactual scenario of no ban. Our estimate is considerably larger than the estimate of Restrepo and Rieger (2016a), which suggests that after 3 years of policy implementation the CVD-attributable mortality rate dropped by 14.2 deaths per 100,000 inhabitants. After 3 years of the de facto TFA policy intervention, our estimates indicate that CVD mortality rate decreased by 19 deaths per 100,000 inhabitants. Given that our sample is spatially and temporally larger, and that we employ a larger set of covariates than Restrepo and Rieger (2016a), the difference in the death rates in Denmark and its synthetic control group could be attributed to a different set of covariates while other empirical factors include a different follow-up period, different set of countries and a different policy date. In 2012, namely, the last year of the Restrepo and Rieger (2016a) estimation sample, our estimate shows a drop in the CVD death rate by 26 deaths per 100,000 inhabitants compared to 22 deaths per 100,000 found by Restrepo and Rieger (2016a). The difference in the estimates could be also attributed to the fact we use a larger set of covariates. Moreover, our pre-2001 prediction error is 0.074 , which implies the discrepancy between the actual Denmark and the synthetic Denmark is within a limit of $10 \%$, and is unlikely to draw a counterfactual scenario that would be a statistical artifact capturing trends distinct from the de facto TFA ban in 2001. Table 2 reports the covariate-specific means for Denmark and its synthetic control group before the policy intervention in 2001. The mean comparisons indicate a very close covariate-level match between Denmark and its synthetic counterpart but do not contain any notion of statistical significance.

The synthetic control group's composition is crucial for explaining the differences in the CVD death rate between the actual Denmark and its artificial counterpart. Prior to the estimation, from the donor pool we excluded five countries that had passed similar laws after 2001; namely, Switzerland, Austria, Iceland, and Norway. This left 32 candidate countries in the donor pool. The synthetic Denmark that best captures the CVD death rate trend before 2001 consists of Australia (88.8\%) and Finland (11.2\%). This implies that Australia and Finland tend to best reproduce the trajectory of Denmark's CVD-related death rate prior to the de facto policy intervention in 2001. Table 3 reports the Danish synthetic control group's composition for the full set of outcomes. Our results do not imply that absence of the ban would lead to a rising CVD-attributed death rate. On the contrary, a decreasing trend in death rates is seen in both Denmark and the synthetic control group before the de facto ban in 2001. The synthetic control estimates from Fig. 1 clearly imply that, without the ban, the CVD death rate would decrease much slower than the rapid decrease seen after the de facto policy intervention in 2001. In addition, the gap in the observed CVD death rate and the death rate of Denmark's synthetic control group appears to be increasing over time, suggesting the policy intervention's impact is not only large in magnitude but also far-reaching. Since the countries that passed similar legislation later are excluded from the donor pool, it is unlikely that spatial spillovers and the endogeneity concerns would jeopardize our estimate. 
Table 1 Descriptive statistics

\begin{tabular}{|c|c|c|c|c|c|}
\hline & \# Obs & Mean & StD & Min & Max \\
\hline \multicolumn{6}{|l|}{ Panel A: outcomes } \\
\hline CVD death rate & 988 & 192.01 & 132.04 & 25.6 (South Korea) & 651.1 (Estonia) \\
\hline Adult obesity rate & 988 & 17.69 & 5.43 & 1.5 (Japan) & 35.6 (USA) \\
\hline Adolescent obesity rate & 988 & 6.89 & 3.28 & 1.4 (Slovakia) & 21.2 (USA) \\
\hline Child obesity rate & 988 & 9.05 & 3.72 & 2.1 (Slovakia) & 22.5 (USA) \\
\hline Fraction overweight & 988 & 51.82 & 8.25 & 18.4 (Japan) & 67.4 (USA) \\
\hline Body mass index & 988 & 25.71 & 1.05 & 22.3 (Japan) & 28.8 (USA) \\
\hline \multicolumn{6}{|l|}{ Panel B: covariates } \\
\hline Food demand structure (first principal component) & 988 & 0.000 & 3.80 & -6.09 (Latvia) & 7.06 (USA) \\
\hline Food demand structure (second principal component) & 988 & -0.000 & 1.18 & -6.88 (USA) & 0.74 (Switzerland) \\
\hline Log health expenditure in 2000 & 38 & 7.17 & 1.71 & 3.99 (South Korea) & 12.50 (USA) \\
\hline Consumer price index in 1990 & 38 & 43.29 & 28.41 & 0.0008 (Brazil) & 100 (Germany) \\
\hline Consumer price index in 1995 & 38 & 59.69 & 20.90 & 6.33 (Russia) & 101.07 (Japan) \\
\hline Consumer price index in 2000 & 38 & 73.44 & 14.09 & 30.76 (Russia) & 102.65 (Japan) \\
\hline Consumer price index growth in 1990 & 38 & 107.21 & 484.48 & - 3.11 (Sweden) & 2960 (Brazil) \\
\hline Consumer price index growth in 1995 & 38 & 16.09 & 33.34 & - 0.12 (Japan) & 197.47 (Russia) \\
\hline Consumer price index growth in 2000 & 38 & 4.55 & 4.22 & - 0.65 (Switzerland) & 20.77 (Russia) \\
\hline Latitude & 988 & 38.45 & 26.69 & - 40.90 (New Zealand) & 64.96 (Iceland) \\
\hline Longitude & 988 & 10.54 & 62.61 & - 103.34 (Canada) & 174.88 (New Zealand) \\
\hline Share of age-dependent population & 988 & 50.16 & 5.71 & 36.32 (South Korea) & 76.42 (Mexico) \\
\hline Birth rate & 988 & 12.76 & 3.92 & 7.60 (Latvia) & 28.54 (Mexico) \\
\hline IQ & 988 & 96.94 & 4.72 & 84 (Colombia) & 106 (South Korea) \\
\hline Population growth & 988 & 0.55 & 0.80 & -2.57 (Estonia) & 6.01 (Israel) \\
\hline Systolic blood pressure & 988 & 26.15 & 5.94 & 11 (South Korea) & 40.75 (Lithuania) \\
\hline Life expectancy & 988 & 76.88 & 3.94 & 64.46 (Russia) & 83.84 (Japan) \\
\hline Log GDP per capita & 988 & 9.58 & 0.49 & 8.40 (Russia) & 10.40 (USA) \\
\hline Log GDP per capita in 1990 & 38 & 9.36 & 0.46 & 8.46 (Costa Rica) & 10.05 (USA) \\
\hline Log GDP per capita in 1995 & 38 & 9.38 & 0.51 & 8.47 (Russia) & 10.11 (USA) \\
\hline Log GDP per capita in 2000 & 38 & 9.54 & 0.51 & 8.56 (Russia) & 10.26 (USA) \\
\hline Fruit intake & 988 & 94.43 & 33.88 & 18 (Lithuania) & 188 (Israel) \\
\hline Vegetables intake & 988 & 104.75 & 48.57 & 23 (Colombia) & 302 (Greece) \\
\hline Sugar intake & 988 & 43.17 & 10.70 & 16 (Slovenia) & 71 (USA) \\
\hline Protein intake & 988 & 99.13 & 14.41 & 56 (Colombia) & 140 (Iceland) \\
\hline Fat intake & 988 & 123.64 & 28.04 & 58 (South Korea) & 176 (Austria) \\
\hline Calories intake & 988 & 3272.52 & 289.43 & 2538 (Estonia) & 3858\ (Austria) \\
\hline
\end{tabular}

The effects of the de facto TFA policy intervention on the obesity rate suggest the ban is associated with a decrease in obesity rates among children and adolescents although, while the effect on adult obesity rates is positive, it is particularly weak. In Fig. 1, panel (b) presents the impacts of the TFA policy intervention on the adult obesity rate. Prior to 2001, there is almost no discrepancy at all in the adult obesity rate between Denmark and its synthetic counterpart with pre-2001 RMSE at $0.1 \%$. After 2001, Denmark's adult obesity rate closely resembles the adult obesity trend of the synthetic control group, albeit it appears slightly higher than the control group level by 2015. In 2015, the difference in the adult obesity rate between Denmark and its synthetic control group is 0.4 of a percentage point, suggesting that the TFA policy intervention is not associated with a drop in the adult obesity rate compared to the highly favorable impact of the policy intervention on the CVD death rate. The adult obesity rate in Denmark before the TFA policy intervention in 2001 is best reproduced by a 


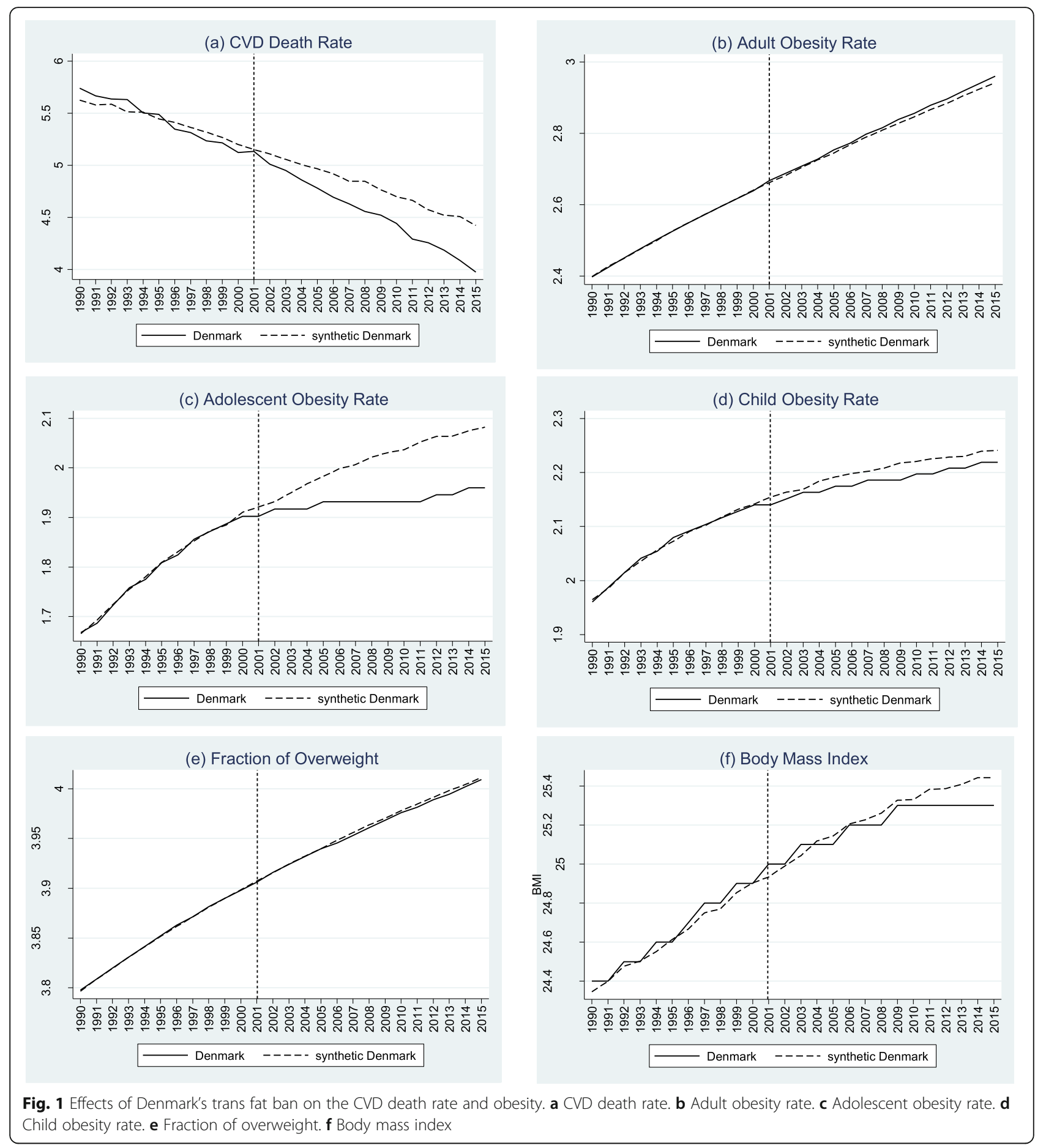

combination of Belgium (48\%), Germany (22\%), the USA (10\%), South Korea (6\%), Japan (5\%), Estonia (4\%), and Canada (2\%).

On the contrary, the TFA policy intervention in 2001 is associated with a substantial slowdown in adolescent obesity rate and with a very modest drop in child obesity rate. The TFA ban's effects on the adolescent obesity rate are particularly strong. Our estimates indicate a clear divergence of the adolescent obesity rate between the actual Denmark and the synthetic Denmark after the 2001 policy intervention. By 2015, our synthetic control estimates indicate an adolescent obesity rate in synthetic Denmark of $8 \%$ while the observed adolescent obesity rate in the actual Denmark is $7.1 \%$, which suggests the de facto TFA ban in 2001 is associated with about a 1-percentage point drop in the obesity rate of the adolescent age group relative to pre-2001 synthetic Denmark. 
Table 2 Covariate means in synthetic Denmark

\begin{tabular}{|c|c|c|c|c|c|c|c|c|c|c|c|c|}
\hline & \multicolumn{2}{|c|}{$\begin{array}{l}\text { Log cardiovascular } \\
\text { disease death rate }\end{array}$} & \multicolumn{2}{|c|}{$\begin{array}{l}\text { Log adult obesity } \\
\text { rate }\end{array}$} & \multicolumn{2}{|c|}{$\begin{array}{l}\text { Log adolescent } \\
\text { obesity rate }\end{array}$} & \multicolumn{2}{|c|}{$\begin{array}{l}\text { Log child } \\
\text { obesity rate }\end{array}$} & \multicolumn{2}{|c|}{$\begin{array}{l}\text { Log fraction } \\
\text { of overweight }\end{array}$} & \multicolumn{2}{|c|}{ Body mass index } \\
\hline & Denmark & $\begin{array}{l}\text { Synthetic } \\
\text { Denmark }\end{array}$ & Denmark & $\begin{array}{l}\text { Synthetic } \\
\text { Denmark }\end{array}$ & Denmark & $\begin{array}{l}\text { Synthetic } \\
\text { Denmark }\end{array}$ & Denmark & $\begin{array}{l}\text { Synthetic } \\
\text { Denmark }\end{array}$ & Denmark & $\begin{array}{l}\text { Synthetic } \\
\text { Denmark }\end{array}$ & Denmark & $\begin{array}{l}\text { Synthetic } \\
\text { Denmark }\end{array}$ \\
\hline $\begin{array}{l}\text { Outcome variable } \\
\text { in } 1990\end{array}$ & 5.74 & 5.63 & 2.40 & 2.40 & 1.67 & 1.67 & 1.96 & 1.96 & 3.80 & 3.80 & 24.40 & 24.35 \\
\hline $\begin{array}{l}\text { Outcome variable } \\
\text { in } 1995\end{array}$ & 5.49 & 5.45 & 2.53 & 2.53 & 1.81 & 1.81 & 2.08 & 2.07 & 3.85 & 3.85 & 24.60 & 24.61 \\
\hline $\begin{array}{l}\text { Outcome variable } \\
\text { in } 2000\end{array}$ & 5.12 & 5.20 & 2.64 & 2.64 & 1.90 & 1.91 & 2.14 & 2.14 & 3.90 & 3.90 & 24.90 & 24.90 \\
\hline $\begin{array}{l}\text { Food demand } \\
\text { structure (first p.c.) }\end{array}$ & 5.50 & 3.78 & 5.50 & 3.36 & 5.50 & 4.45 & 5.50 & 4.15 & 5.50 & 3.01 & 5.50 & 3.25 \\
\hline $\begin{array}{l}\text { Food demand } \\
\text { structure (second } \\
\text { p.c.) }\end{array}$ & 0.71 & 0.58 & 0.71 & -0.27 & 0.71 & -1.32 & 0.71 & -0.84 & 0.71 & 0.50 & 0.71 & 0.52 \\
\hline $\begin{array}{l}\text { Log health } \\
\text { expenditure in } \\
2000\end{array}$ & 2.09 & 2.02 & 2.09 & 2.09 & 2.09 & 2.20 & 2.09 & 2.14 & 2.09 & 2.08 & 2.09 & 2.06 \\
\hline $\begin{array}{l}\text { Consumer price } \\
\text { index in } 1990\end{array}$ & 66.11 & 61.01 & 66.11 & 70.87 & 66.11 & 74.88 & 66.11 & 70.17 & 66.11 & 79.88 & 66.11 & 77.83 \\
\hline $\begin{array}{l}\text { Consumer price } \\
\text { index in } 1995\end{array}$ & 72.86 & 68.92 & 72.86 & 74.72 & 72.86 & 80.55 & 72.86 & 78.63 & 72.86 & 79.45 & 72.86 & 80.32 \\
\hline $\begin{array}{l}\text { Consumer price } \\
\text { index in } 2000\end{array}$ & 81.68 & 75.65 & 81.68 & 82.10 & 81.68 & 86.34 & 81.68 & 84.71 & 81.68 & 84.97 & 81.68 & 86.02 \\
\hline $\begin{array}{l}\text { Consumer price } \\
\text { index growth }\end{array}$ & 2.18 & 2.63 & 2.18 & 2.74 & 2.18 & 2.07 & 2.18 & 2.14 & 2.18 & 1.28 & 2.18 & 1.47 \\
\hline $\begin{array}{l}\text { Consumer price } \\
\text { index growth in } \\
1990\end{array}$ & 2.65 & 6.99 & 2.65 & 3.92 & 2.65 & 3.97 & 2.65 & 3.75 & 2.65 & 3.47 & 2.65 & 2.71 \\
\hline $\begin{array}{l}\text { Consumer price } \\
\text { index growth in } \\
1995\end{array}$ & 2.10 & 4.10 & 2.10 & 2.95 & 2.10 & 1.69 & 2.10 & 1.44 & 2.10 & 1.58 & 2.10 & 1.42 \\
\hline $\begin{array}{l}\text { Consumer price } \\
\text { index growth in } \\
2000\end{array}$ & 2.92 & 4.27 & 2.92 & 2.27 & 2.92 & 1.87 & 2.92 & 2.14 & 2.92 & 2.13 & 2.92 & 1.65 \\
\hline Latitude & 56.29 & -15.50 & 56.29 & 47.98 & 56.29 & 43.66 & 56.29 & 45.52 & 56.29 & 48.89 & 56.29 & 49.06 \\
\hline Longitude & 9.50 & 121.67 & 9.50 & 8.83 & 9.50 & 10.20 & 9.50 & 8.84 & 9.50 & 26.66 & 9.50 & 28.17 \\
\hline $\begin{array}{l}\text { Share of age- } \\
\text { dependent } \\
\text { population }\end{array}$ & 48.82 & 49.91 & 48.82 & 48.99 & 48.82 & 49.59 & 48.82 & 50.12 & 48.82 & 48.87 & 48.82 & 47.66 \\
\hline Birth rate & 12.80 & 13.93 & 12.80 & 11.73 & 12.80 & 12.02 & 12.80 & 11.98 & 12.80 & 11.26 & 12.80 & 11.26 \\
\hline IQ & 98.00 & 98.11 & 98.00 & 99.69 & 98.00 & 100.05 & 98.00 & 99.87 & 98.00 & 99.35 & 98.00 & 100.15 \\
\hline $\begin{array}{l}\text { Population } \\
\text { growth }\end{array}$ & 0.36 & 1.09 & 0.36 & 0.41 & 0.36 & 0.54 & 0.36 & 0.46 & 0.36 & 0.41 & 0.36 & 0.41 \\
\hline $\begin{array}{l}\text { Systolic blood } \\
\text { pressure }\end{array}$ & 30.33 & 25.79 & 30.33 & 26.32 & 30.33 & 24.56 & 30.33 & 23.98 & 30.33 & 29.34 & 30.33 & 27.93 \\
\hline Life expectancy & 75.59 & 77.86 & 75.59 & 76.34 & 75.59 & 77.43 & 75.59 & 77.24 & 75.59 & 77.02 & 75.59 & 77.43 \\
\hline $\begin{array}{l}\text { Log GDP per } \\
\text { capita }\end{array}$ & 9.92 & 9.83 & 9.92 & 9.79 & 9.92 & 9.92 & 9.92 & 9.90 & 9.92 & 9.79 & 9.92 & 9.82 \\
\hline $\begin{array}{l}\text { Log GDP per } \\
\text { capita in } 1990\end{array}$ & 9.82 & 9.75 & 9.82 & 9.71 & 9.82 & 9.85 & 9.82 & 9.82 & 9.82 & 9.73 & 9.82 & 9.74 \\
\hline $\begin{array}{l}\text { Log GDP per } \\
\text { capita in } 1995\end{array}$ & 9.92 & 9.82 & 9.92 & 9.78 & 9.92 & 9.91 & 9.92 & 9.89 & 9.92 & 9.77 & 9.92 & 9.81 \\
\hline $\begin{array}{l}\text { Log GDP per } \\
\text { capita in } 2000\end{array}$ & 10.05 & 9.97 & 10.05 & 9.92 & 10.05 & 10.03 & 10.05 & 10.01 & 10.05 & 9.91 & 10.05 & 9.93 \\
\hline
\end{tabular}


Table 2 Covariate means in synthetic Denmark (Continued)

\begin{tabular}{|c|c|c|c|c|c|c|c|c|c|c|c|c|}
\hline & \multicolumn{2}{|c|}{$\begin{array}{l}\text { Log cardiovascular } \\
\text { disease death rate }\end{array}$} & \multicolumn{2}{|c|}{$\begin{array}{l}\text { Log adult obesity } \\
\text { rate }\end{array}$} & \multicolumn{2}{|c|}{$\begin{array}{l}\text { Log adolescent } \\
\text { obesity rate }\end{array}$} & \multicolumn{2}{|c|}{$\begin{array}{l}\text { Log child } \\
\text { obesity rate }\end{array}$} & \multicolumn{2}{|c|}{$\begin{array}{l}\text { Log fraction } \\
\text { of overweight }\end{array}$} & \multicolumn{2}{|c|}{ Body mass index } \\
\hline & Denmark & $\begin{array}{l}\text { Synthetic } \\
\text { Denmark }\end{array}$ & Denmark & $\begin{array}{l}\text { Synthetic } \\
\text { Denmark }\end{array}$ & Denmark & $\begin{array}{l}\text { Synthetic } \\
\text { Denmark }\end{array}$ & Denmark & $\begin{array}{l}\text { Synthetic } \\
\text { Denmark }\end{array}$ & Denmark & $\begin{array}{l}\text { Synthetic } \\
\text { Denmark }\end{array}$ & Denmark & $\begin{array}{l}\text { Synthetic } \\
\text { Denmark }\end{array}$ \\
\hline Log fruit intake & 4.35 & 4.46 & 4.35 & 4.36 & 4.35 & 4.37 & 4.35 & 4.31 & 4.35 & 4.40 & 4.35 & 4.45 \\
\hline $\begin{array}{l}\text { Log vegetables } \\
\text { intake }\end{array}$ & 4.37 & 4.43 & 4.37 & 4.70 & 4.37 & 4.73 & 4.37 & 4.78 & 4.37 & 4.46 & 4.37 & 4.55 \\
\hline Log sugar intake & 3.91 & 3.83 & 3.91 & 3.90 & 3.91 & 3.90 & 3.91 & 3.99 & 3.91 & 3.81 & 3.91 & 3.84 \\
\hline Log protein intake & 4.65 & 4.63 & 4.65 & 4.58 & 4.65 & 4.63 & 4.65 & 4.61 & 4.65 & 4.58 & 4.65 & 4.58 \\
\hline Log fat intake & 4.90 & 4.85 & 4.90 & 4.92 & 4.90 & 4.91 & 4.90 & 4.95 & 4.90 & 4.92 & 4.90 & 4.91 \\
\hline Log calories intake & 8.11 & 8.03 & 8.11 & 8.15 & 8.11 & 8.15 & 8.11 & 8.18 & 8.11 & 8.10 & 8.11 & 8.11 \\
\hline
\end{tabular}

As with the CVD death rate, the countries introducing similar TFA policies later are excluded from the donor pool. More specifically, the synthetic Denmark capturing the pre2001 adolescent obesity trends consists of Belgium (48\%), Germany (22\%), the USA (10\%), South Korea (6\%), Japan (5\%), Estonia (4\%), and Canada (2\%). Given the small size of the pre-2001 prediction error $(=0.003)$, the effect is unlikely to be determined by non-TFA policy factors.

One caveat should be kept in mind. Our estimates indicate a relatively minor slowdown of child obesity rate in the postintervention period. Pointwise, the child obesity rate of synthetic Denmark in 2015 is $9.3 \%$ and is only 0.1 percentage points higher than the rate in the actual Denmark. Notice that by 2015, the obesity gap between Denmark and its synthetic control group almost disappears. In our view, the discrepancy in the child obesity rate between real Denmark and its synthetic counterpart highlights a small short-run or temporary effect whereas there is clearly insufficient evidence for lasting long-run child obesity effect of the TFA intervention. Similar to the adolescent obesity rate, the synthetic Denmark consist of the similar countries' weight average of public health outcomes and covariates, albeit in different proportions, namely Belgium (63\%), the USA (18\%), Japan (17\%), and Canada $(<1 \%)$.

Whereas our findings show no discernible effects of the TFA ban on the fraction of overweight, the synthetic control estimates suggest the impact on average body mass index (BMI) appear to be relatively weak. Before 2001, the discrepancy between actual Denmark's BMI and its synthetic counterpart appears very small (= 0.023 ) and within the $10 \%$ bound. The set of countries from the control sample that best captures the BMI trend of actual Denmark consists of Belgium (31\%), the Netherlands (27\%), Germany (22\%), Japan (16\%), and Sweden (3\%), which appears to be in line with the synthetic control group's composition for other outcomes. Our evidence suggests an unclear and imperceptible structural break around the time of the TFA policy intervention. By 2015, the difference in BMI between Denmark and its synthetic control group amounts to
0.11 of a basis point, indicating the effect of the TFA policy intervention is quantitatively small.

In Fig. 2, we compare the trends in CVD death rate of Denmark and its synthetic control group before and after 2001 to assess whether the TFA policy is associated with the differential post-intervention trends. The figure plots the linear trends in the CVD death rate before and after the intervention for both Denmark and its synthetic control group. The graphical evidence clearly suggests a marked similarity of trends in pre-2001 period as well as a noticeable divergence of trends in the post-2001 period, where the drop in CVD death rate in Denmark appears to be considerably greater compared to the synthetic control group. In Table 4, we present trend slope coefficients and the associated 95\% confidence bounds for the mortality level before and after the intervention. In the next step, we compare the change in the slope of actual Denmark in pre- vs. post-reform period with the corresponding change in the slope of synthetic Denmark in the pre- vs. post-reform period using triple difference setup. This allows us to determine whether the TFA policy intervention induced the structural break in the mortality rate. Using a simple Chow test, we fail to reject the null hypothesis on the differential trend $(p$ value $=0.048)$ at conventional $5 \%$ level, which allows us to conclude that TFA policy intervention most likely induced a structural break in the mortality rate.

\subsection{Robustness checks \\ 5.2.1 "In-Space" placebo checks}

To assess whether the effects of the de facto TFA ban are specific to the CVD death rate and obesity rates, we conduct several placebo tests. The first placebo test is to re-assign the de facto 2001 policy intervention to every country in our sample, except those that introduced similar TFA policy interventions in subsequent years. ${ }^{18}$ By reassigning the de facto

\footnotetext{
${ }^{18}$ This implies that Switzerland, Austria, Hungary, Iceland, and Norway are excluded from the TFA policy reassignment as they introduced similar versions of the TFA policy at later dates.
} 
Table 3 Composition of synthetic control groups and weights in synthetic Denmark

\begin{tabular}{|c|c|c|c|c|c|c|}
\hline & $\begin{array}{l}\text { Cardiovascular disease death } \\
\text { rate }\end{array}$ & $\begin{array}{l}\text { Adult obesity } \\
\text { rate }\end{array}$ & $\begin{array}{l}\text { Adolescent obesity } \\
\text { rate }\end{array}$ & $\begin{array}{l}\text { Child obesity } \\
\text { rate }\end{array}$ & $\begin{array}{l}\text { Fraction } \\
\text { overweight }\end{array}$ & $\begin{array}{l}\text { Body mass } \\
\text { index }\end{array}$ \\
\hline RMSE & 0.074 & 0.001 & 0.003 & 0.003 & 0.0004 & 0.023 \\
\hline Australia & 0.888 & 0 & 0 & 0 & 0.053 & 0 \\
\hline Austria & - & - & - & - & - & - \\
\hline Belgium & 0 & 0.482 & 0.33 & 0.633 & 0.25 & 0.307 \\
\hline Brazil & 0 & 0 & 0 & 0 & 0 & 0 \\
\hline Canada & 0 & 0.026 & 0 & 0.005 & 0 & 0 \\
\hline Chile & 0 & 0 & 0 & 0 & 0 & 0 \\
\hline Colombia & 0 & 0 & 0 & 0 & 0 & 0 \\
\hline Costa Rica & 0 & 0 & 0 & 0 & 0 & 0 \\
\hline Czechia & 0 & 0 & 0 & 0 & 0 & 0 \\
\hline Estonia & 0 & 0.042 & 0 & 0 & 0 & 0 \\
\hline Finland & 0.112 & 0 & 0 & 0 & 0.208 & 0 \\
\hline France & 0 & 0 & 0.085 & 0 & 0 & 0 \\
\hline Germany & 0 & 0.224 & 0.099 & 0 & 0.328 & 0.220 \\
\hline Greece & 0 & 0 & 0 & 0 & 0 & 0 \\
\hline Hungary & - & - & - & - & - & - \\
\hline Iceland & - & - & - & - & - & - \\
\hline Ireland & 0 & 0 & 0 & 0 & 0 & 0 \\
\hline Israel & 0 & 0 & 0 & 0 & 0 & 0 \\
\hline Italy & 0 & 0 & 0 & 0 & 0 & 0 \\
\hline Japan & 0 & 0.054 & 0.227 & 0.176 & 0.06 & 0.162 \\
\hline Latvia & 0 & 0 & 0 & 0 & 0 & 0 \\
\hline Lithuania & 0 & 0 & 0 & 0 & 0 & 0 \\
\hline Mexico & 0 & 0 & 0 & 0 & 0 & 0 \\
\hline Netherlands & 0 & 0 & 0.008 & 0 & 0.038 & 0.275 \\
\hline $\begin{array}{l}\text { New } \\
\text { Zealand }\end{array}$ & 0 & 0 & 0 & 0 & 0 & 0 \\
\hline Norway & - & - & - & - & - & - \\
\hline Poland & 0 & 0 & 0 & 0 & 0 & 0 \\
\hline Portugal & 0 & 0 & 0 & 0 & 0 & 0 \\
\hline Russia & 0 & 0 & 0.001 & 0 & 0 & 0 \\
\hline Slovakia & 0 & 0 & 0 & 0 & 0 & 0 \\
\hline Slovenia & 0 & 0 & 0 & 0 & 0 & 0 \\
\hline South Korea & 0 & 0.067 & 0 & 0 & 0 & 0 \\
\hline Sweden & 0 & 0 & 0 & 0 & 0.063 & 0.035 \\
\hline Switzerland & - & - & - & - & - & - \\
\hline UK & 0 & 0 & 0 & 0 & 0 & 0 \\
\hline USA & 0 & 0.105 & 0.251 & 0.186 & 0 & 0 \\
\hline
\end{tabular}

TFA policy intervention in 2001 to all unaffected countries, we are able to perform a key internal validity check on whether the counterfactual outcomes are plausible. In particular, for each outcome, we construct the set of 32 (= \#countries in the sample minus one treated country) placebo reassignments.
One caveat concerning the unrestricted placebo check is that pre-2001 fit may be poor for some countries in the donor pool, which may affect the statistical inference. We follow Abadie et al. (2010) and leave out countries for which the pre-2001 root mean square prediction error (RMSE) is at most twice the size of 


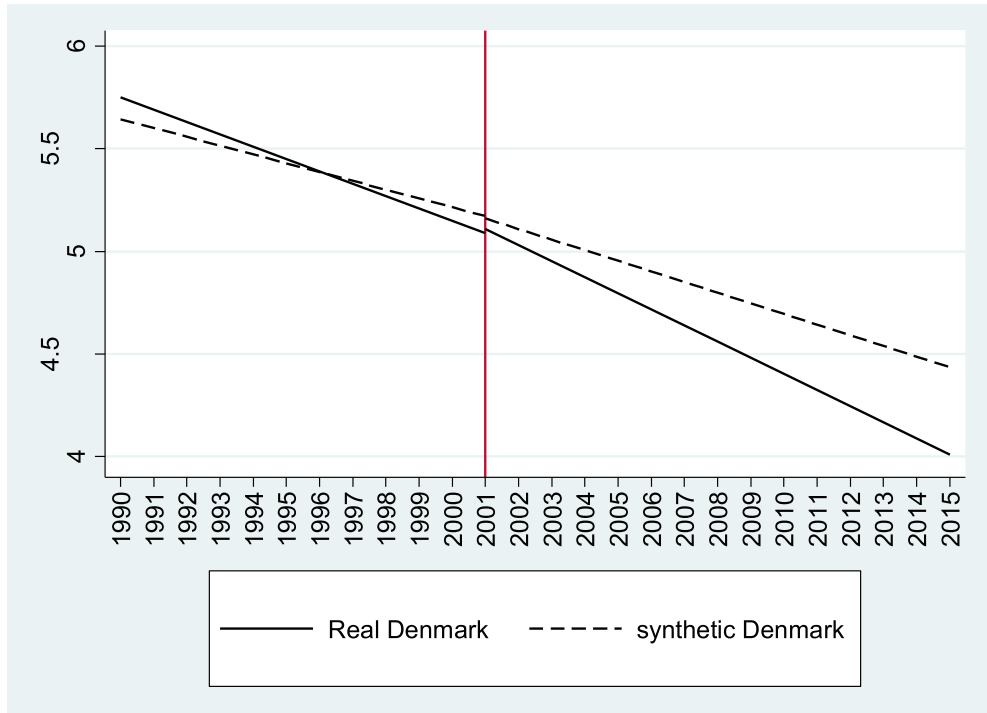

Fig. 2 Cardiovascular mortality trend comparison

Denmark's RMSE. We further tackle the internal validity of our estimates and compute the probabilities that the TFA policy intervention's impact is observed by chance (Galiani and Quistorff 2017). The underlying notion is that if the decline in the CVD death and obesity rates is attributable to the 2001 policy intervention, the probability the effects are observed by chance should be very low. By contrast, if factors other than the TFA ban are attributable to the post2001 change in public health outcomes, internal placebo distributions should show the post-2001 effects of the ban are as large as the main effects. In that case, the probability the effects are randomly driven should be non-trivial.

Our randomization inference is non-parametric, which implies we do not impose any distribution. More specifically, suppose that $\tilde{\lambda}_{1 t}^{\text {Placebo }}=\left\{\hat{\lambda}_{j t}: j \neq 1\right\}$ denotes the internal distribution of placebos for the estimated effect of the ban described by $\hat{\lambda}_{j t}$. We compute the two-sided $p$ value for each of the 32 possible placebos for every outcome as follows:

$$
p \text { value }=\operatorname{Pr}\left(\left|\tilde{\lambda}_{1 t}^{\text {Placebo }}\right| \geq \hat{\lambda}_{1 t}\right)=\frac{\sum_{j \neq 1}\left(\left|\tilde{\lambda}_{j t}\right| \geq \tilde{\lambda}_{1 t}\right)}{J}
$$

where $J$ denotes the number of possible placebos given the number of countries in the donor pool. Hence, the underlying $p$ value indicates the proportion of countries in the control group whose estimated impact of the TFA policy intervention is at least as large as that of Denmark (the treated country). We further avoid large placebos by using an exact covariate-specific balance between Denmark and the donor pool using the nested optimization route that allows us to partially control for spatially correlated stochastic disturbances and a potentially heteroskedastic distribution of the random error term. We also divide the full set of placebo effects by the pre-2001 match quality parameter captured by the RMSE, and generate the pseudo $t$ test statistics.

How often would we obtain the estimated impact of the de facto TFA ban in 2001 that is at least as large as in Denmark if we were to randomly select other

Table 4 Comparison of trends in cardiovascular mortality before and after the trans fat ban

\begin{tabular}{|c|c|c|c|c|c|}
\hline & \multirow[t]{2}{*}{ Pre-reform slope } & \multirow[t]{2}{*}{ Post-reform slope } & \multicolumn{2}{|c|}{ 95\% confidence bounds } & \multirow{2}{*}{$\begin{array}{l}\text { Chow test } \\
\text { ( } p \text { value) }\end{array}$} \\
\hline & & & Pre-reform & Post-reform & \\
\hline Real Denmark & -0.062 & -0.078 & $\{-0.067,-0.057\}$ & $\{-0.081,-0.075\}$ & 0.048 \\
\hline Synthetic control group & -0.041 & -0.051 & $\{-0.047,-0.036\}$ & $\{-0.053,-0.049\}$ & \\
\hline
\end{tabular}




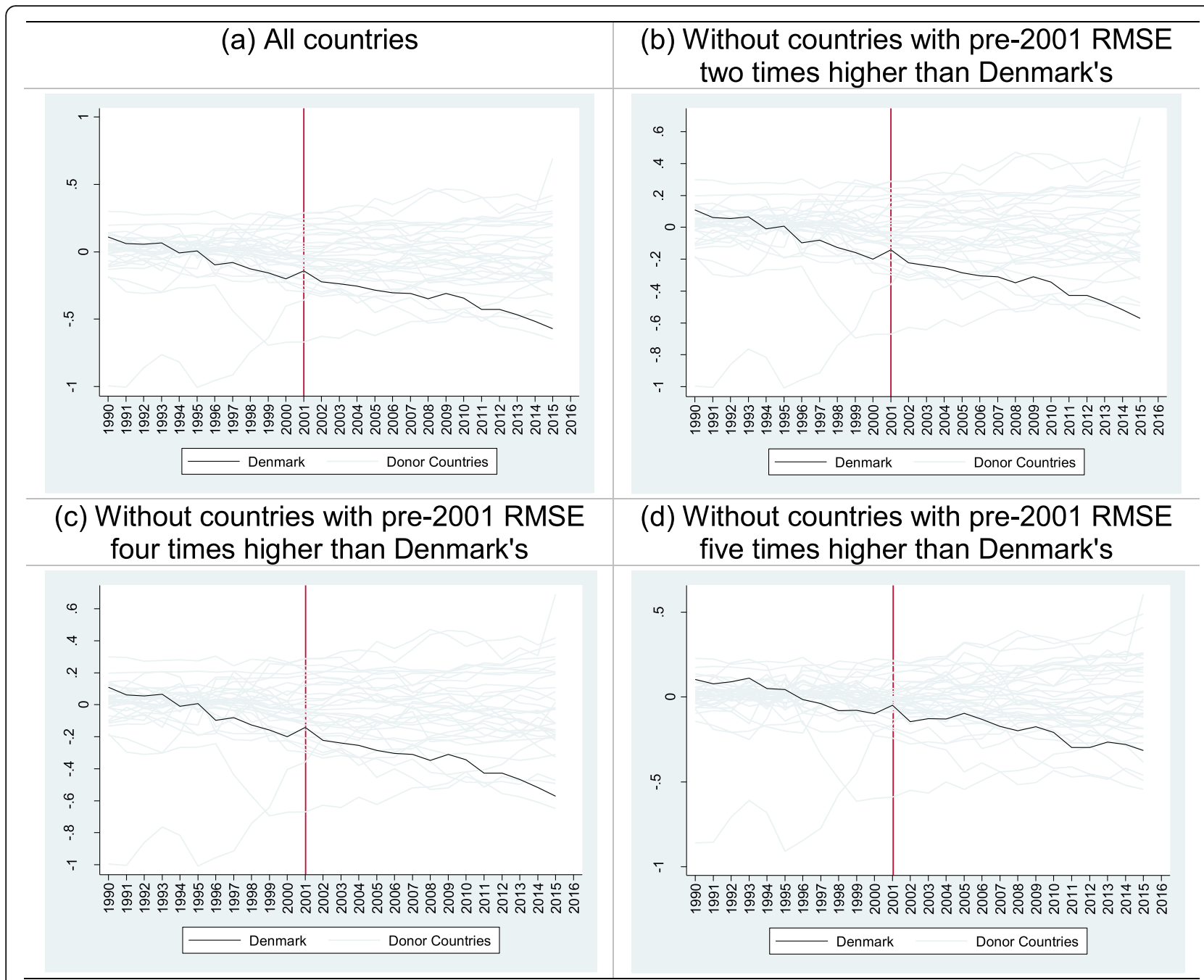

Fig. 3 Cardiovascular disease death rate and placebo distribution in control countries. a All countries. b Without countries with pre-2001 RMSE two times higher than Denmark's. c Without countries with pre-2001 RMSE four times higher than Denmark's. d Without countries with pre-2001 RMSE five times higher than Denmark's

countries as a treatment unit instead of Denmark? Our approach follows the prior literature (Abadie and Gardeazabal 2003, Bertrand et al. 2004). Specifically, we reassign the 2001 TFA policy intervention to those countries that did not implement a similar policy in the same time span as our study (Abadie et al. 2010). Figure 3 presents the results of an "in-space" placebo test. The gray line displays the gap in the CVD death rate for each of 33 placebo runs. It represents the difference in the CVD death rate between each country in the donor pool and its synthetic control group. The solid black line represents the CVD death rate gap difference between Denmark and its synthetic control group. The evidence suggests the gap between Denmark and its synthetic version is becoming larger over time compared to the gaps observed for the countries in the donor pool. For the sake of comparison, panel (a) captures all 33 countries in the placebo run.

In panel (b), we present our baseline in-space placebo distribution where countries with pre-2001 RMSE twice as large as that of Denmark are dropped from the placebo run. The placebo test clearly suggests the same direction of the counterfactual scenario as that obtained for Denmark cannot be plausibly reproduced for other countries in the control sample. This suggests the TFA policy intervention's effects are very likely to be specific to Denmark, and that the same magnitude and direction of the effect is not obtained for other countries that did not pass similar legislation afterwards when the 2001 policy intervention is assigned to them to build a coherent placebo distribution. In panels (c) and (d), we adopt a 
more lenient cutoff and reassess the placebo distributions by excluding countries with a pre-2001 RMSE four and five times as large as Denmark from the donor pool and show the placebo distribution remains intact. Finally, we evaluate Denmark's gap relative to the gaps of countries from the donor pool by looking at the distribution of the ratios of post/pre2001 RMSE. One advantage of comparing ratios is that it is not necessary to choose the cutoff for excluding countries with a poorly fitting pre-policy run. Figure 4 plots the ratio of post/pre-TFA policy intervention for Denmark and all control countries where countries with a pre-2001 RMSE at least four times as large as Denmark's are excluded from the donor pool. On closer inspection, the ratio for Denmark is the highest in the figure. The post-2001 RMSE is about 3.5-times the RMSE of the pre-2001 period. It is quite easy to see that no other country in our sample achieves such a large ratio.

Figure 5 presents the probabilities the obtained TFA policy intervention's effects would happen by chance from the permutation test described by Eq. (5). The graphs display the probability of obtaining the results by chance for every year after the TFA policy intervention in 2001. We extend this kind of randomization inference from the CVD death rate to the remaining outcomes. The evidence suggests the TFA ban is associated with a marked drop in the CVD death rate in the post-ban years as well as with a notable slowdown in the trend of rising obesity. In particular, the probability the effects were obtained at random tends to decrease considerably or remain very low. For example, in panel (a), the results of the permutation test suggest the probability the counterfactual level of the CVD death rate without a ban is obtained at random is less than $10 \%$ in the last year of our estimation period (i.e., 2015), which we regard as evidence that the TFA policy intervention helped reduce CVD-related mortality substantially. Permutation tests for obesity-related outcomes suggest the TFA policy intervention strongly affected adolescent and child obesity rates but had an arguably weaker impact on the adult obesity rate. For instance, the $p$ values in panel (c) clearly show the probability of the adolescent obesity rate slowdown being due to chance is very close to zero throughout the entire postintervention period. The strength of the TFA ban's effect on the child obesity rate appears very high in the initial post-treatment period while the probability of a chance-driven counterfactual child obesity rate jumps to around $20 \%$ by the end of the estimation period. This allows us to conclude the TFA intervention had a strong effect on the adolescent obesity rate, a slightly weaker effect on the child obesity rate, and a weak effect on the adult obesity rate. By contrast, in panel (e), the TFA ban's effects on the fraction of overweight as strong as in the case of adolescent obesity rates while the ban's effects on BMI appear to be weak and statistically nonsignificant.

In Fig. 6, we present the results of an "in-space" placebo test for the adolescent obesity rate. Panel (b), depicts our baseline in-space placebo distribution where countries with pre-2001 RMSE twice as large as that of Denmark are excluded from the placebo run. The placebo test clearly suggests that the same direction of the counterfactual scenario for adolescent

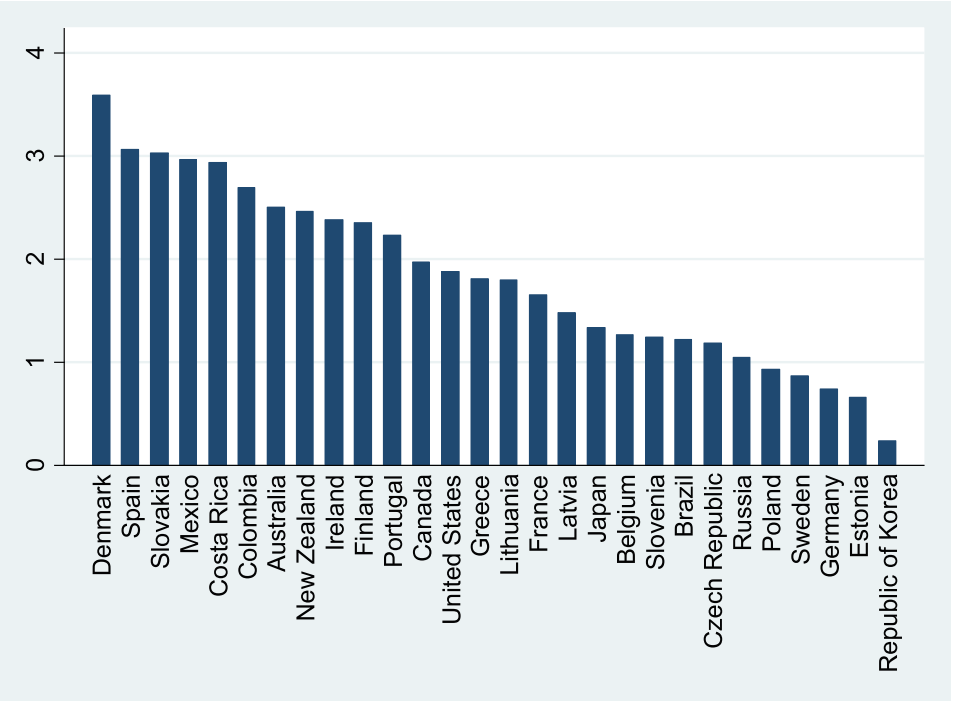

Fig. 4 Ratio of the post-ban RMSE and pre-ban RMSE: Denmark and group countries without a pre-ban RMSE two times higher than Denmark's 


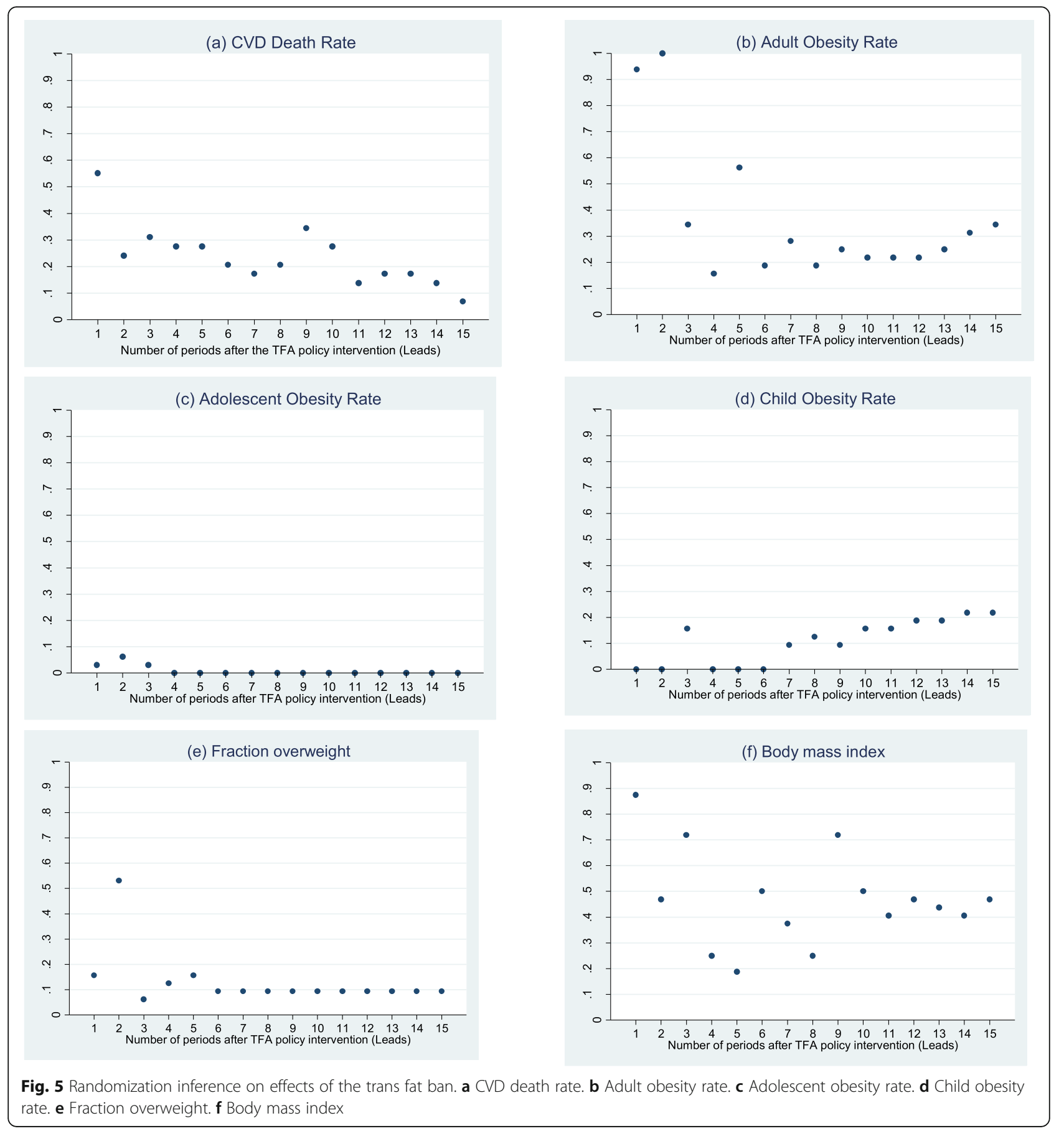

obesity rate as that obtained for Denmark cannot be reasonably reproduced for other countries in the control sample. The evidence thus clearly suggest that the fraction of countries with a similar postintervention adolescent obesity trend is very close to zero for the entire post-intervention period which implies that the obesity effect of the TFA ban is quite likely to be specific to Denmark, and does not seem to be confounded by factors other than the TFA policy intervention. In panels (c) and (d), we adopt more lenient prediction error cutoffs and the results seem to confirm zero pre-intervention gap and a relatively strong non-zero gap in the post-intervention period.

Figure 7 plots the ratio of post/pre-TFA policy intervention RMSE ratio for Denmark and all control countries for adolescent obesity rate where countries 


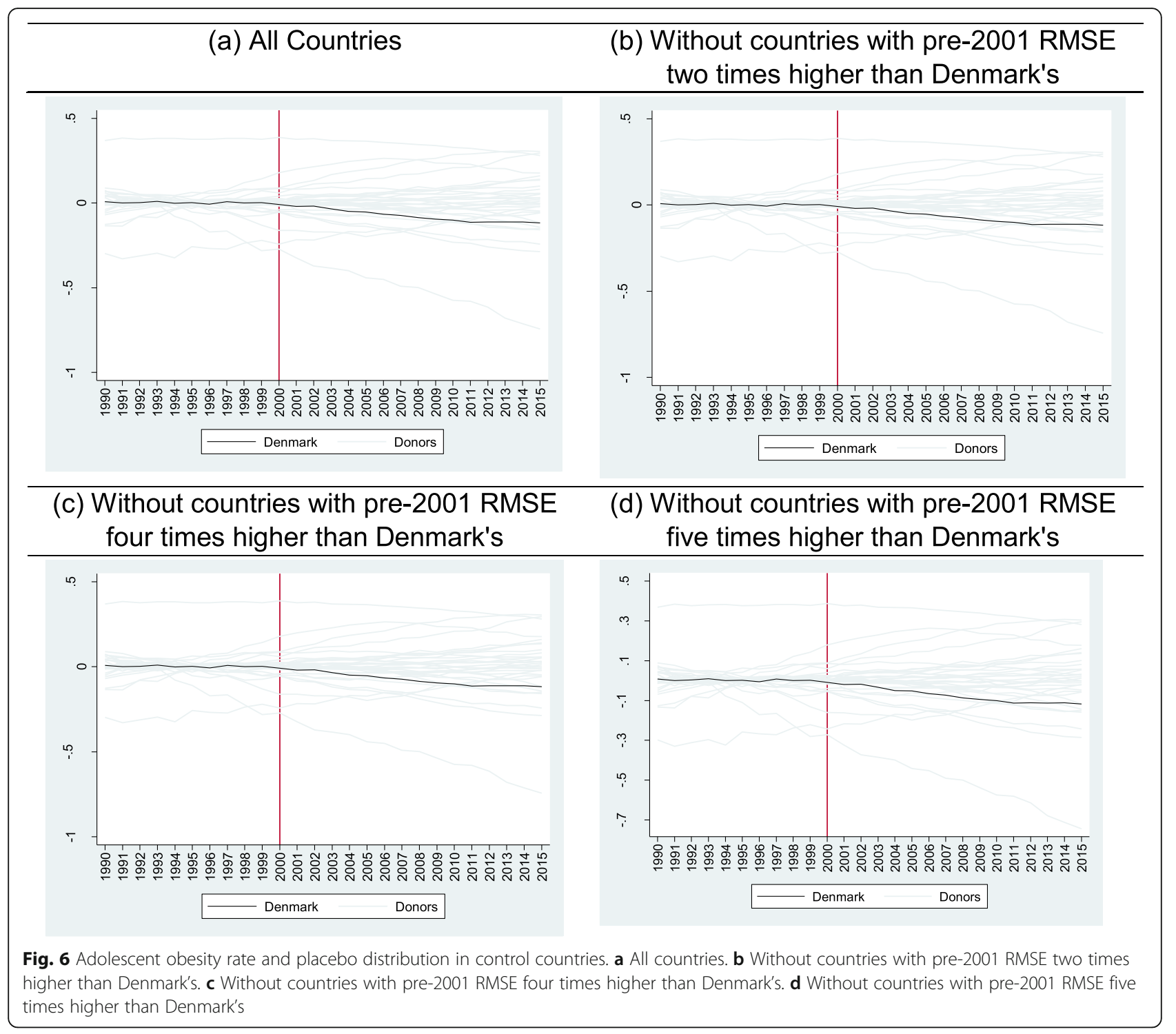

with a pre-2001 RMSE at least four times as large as Denmark's are excluded from the donor pool. The ratio for Denmark is the highest in the figure as not a single country is able to approach such high post/pre2001 RMSE ratio, which confirms the notion that the effect is specific to Denmark and does not seem to be confounded by non-TFA changes in the same year as the policy intervention.

\subsubsection{Effects on unrelated health outcomes}

Our second placebo check is to assess the 2001 policy intervention's impact on public health outcomes theoretically unrelated to the TFA ban. The underlying notion is that if the effects of the TFA ban are specific to CVD mortality and obesity rates, one should not observe the same pattern for public health outcomes unaffected by the TFA ban. We use two

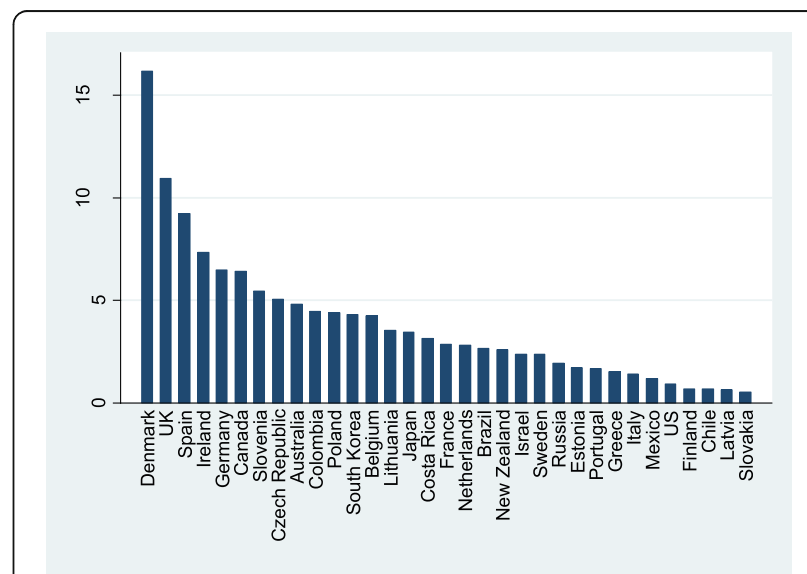

Fig. 7 Ratio of the post-ban RMSE and pre-ban RMSE: Denmark and group countries without a pre-ban RMSE two times higher than Denmark's 
specific public health outcomes to unravel whether the effects of the TFA policy intervention are comparable across non-CVD and non-obesity public health outcomes, namely: (1) smoking cessation rates (Ng et al. 2014) and (2) cancer death rates (Nahgavi et al. 2017). The TFA ban's impact is assessed in the same time span as obesity rates and CVD-related mortality.

Figure 8 presents the effects of the TFA policy intervention in 2001 on both public health outcomes. Panel (a) shows the TFA policy's effects on the prevalence of smoking. Although smoking prevalence exhibits a clear downward trend, the synthetic control estimate does not suggest the TFA ban is associated with a structural break in the prevalence of smoking. If anything, the counterfactual prevalence of smoking in the absence of the ban is clearly driven by the pre2001 trends, with the most likely break occurring in 1998. The synthetic control group for the prevalence of smoking before 2001 does not seem to capture actual Denmark's smoking trend reasonably well as the pre-2001 root mean square error is large compared to the error sizes seen in Fig. 1. Panel (b) exhibits the TFA ban's impact on the cancer death rate. The evidence shows the TFA ban does not seem to be associated with any discernible effect on the cancer death rate. In particular, by re-running the synthetic control algorithm, we find the synthetic control group for pre-2001 Denmark fails to adequately capture the observed cancer death rate, revealing no evidence of the impact of the policy change. We consider this as evidence the TFA policy intervention's impact is specific to CVD death rates and obesity rates but did not seem to affect either smoking cessation or cancer death. The evidence clearly indicates the ability of the TFA ban to affect CVD death rate and obesity levels while having almost no effect on unrelated public health outcomes that could invoke possible confounding issues.

\subsubsection{In-time placebo check}

Our third placebo check is to assign two false years of the TFA policy intervention that might produce different pre-ban and post-ban trends in CVD-related mortality and could affect the counterfactual scenario. We choose two specific dates to perform policy reassignment. First, in 1997, the Danish Nutrition Council released its first official report on the adverse health effects of TFAs in the food supply. This suggests health-minded consumers may have reacted to the report's findings by voluntarily reducing their consumption of TFAs on the grounds of rational choice and without any direct policy intervention. In this instance, the counterfactual scenario would be driven by the break in the CVD death rate between Denmark and its synthetic peer in 1997. Second, in 2007, the Danish government introduced new comprehensive anti-smoking legislation to create smokefree environments, which could have systematically affected the CVD death rate.

In Fig. 9, we present the placebo run for both falsely assigned policy years. In panel (a), the synthetic control estimates do not suggest that the CVD death rate of Denmark and its synthetic control group diverge in the year 1997, which indicates that the CVD mortality drop might not be attributed to the Danish Nutrition Council TFA report. The results do not show any evidence of the break between the CVD death rate of Denmark and its synthetic peer in either 1997 or even the adjacent years. We also confirm that the introduction of anti-smoking legislation in 2007 does not seem to push the counterfactual CVD death (a) Effect of Ban on Smoking Cessation (RMSE $=0.07$ )

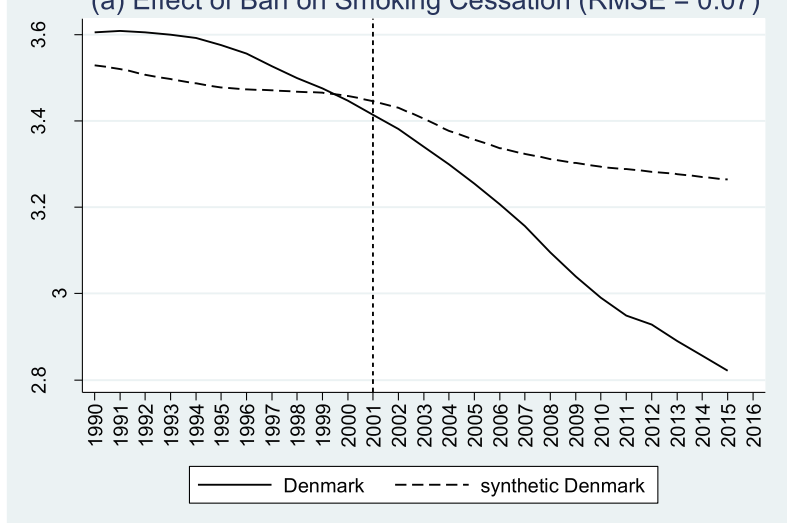

(b) Effect of Ban on Cancer Death Rate (RMSE $=0.100$ )

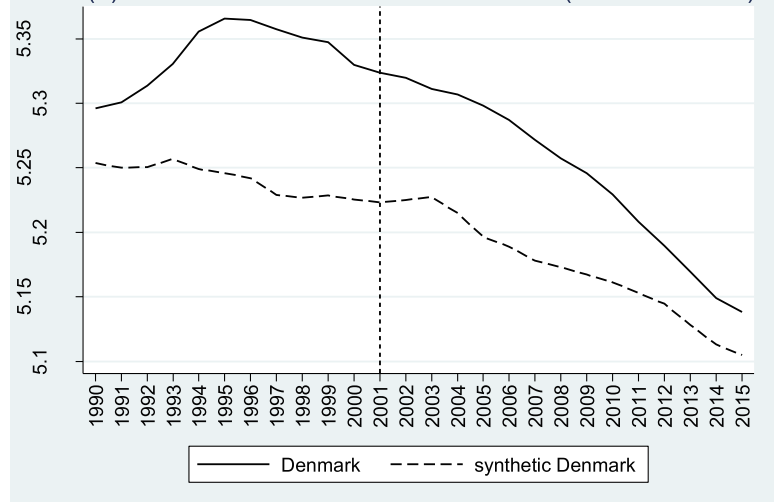

Fig. 8 Effects of the trans fat ban on unrelated public health outcomes. a Effect of ban on smoking cessation (RMSE $=0.07)$. $\mathbf{b}$ Effect of ban on cancer death rate $($ RMSE $=0.100)$ 


\section{Panel A: Synthetic Control Estimates}

(a) 1997 as Placebo Intervention Year (RMSE = 0.06)

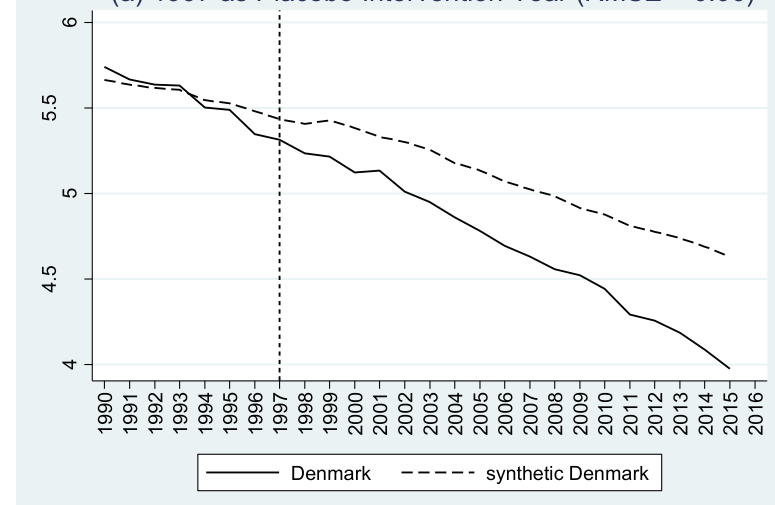

(b) 2007 Placebo Intervention Year (RMSE = 0.27)

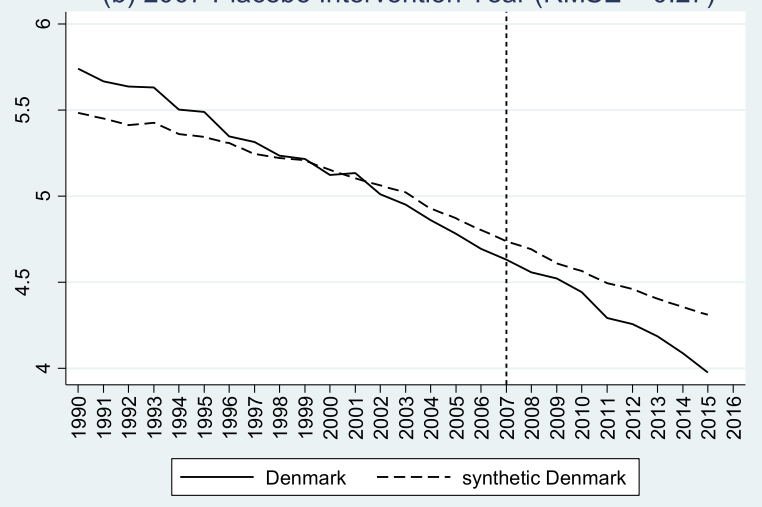

Panel B: Randomization Inference

(a) Placebo Intervention Year $=1997$

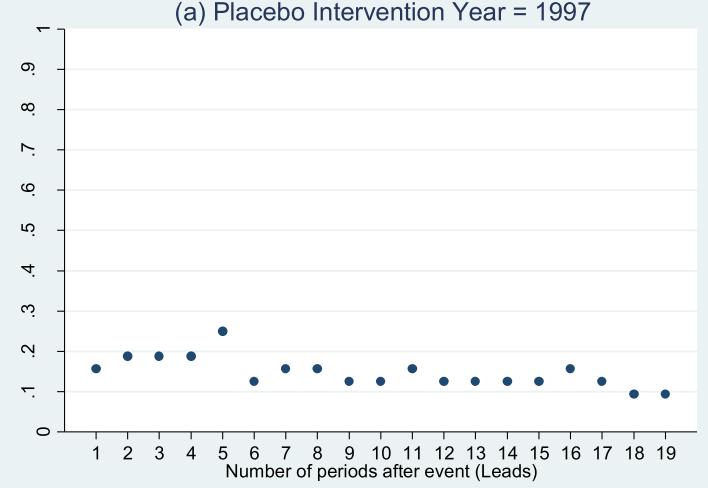

(b) Placebo Intervention Year $=2007$

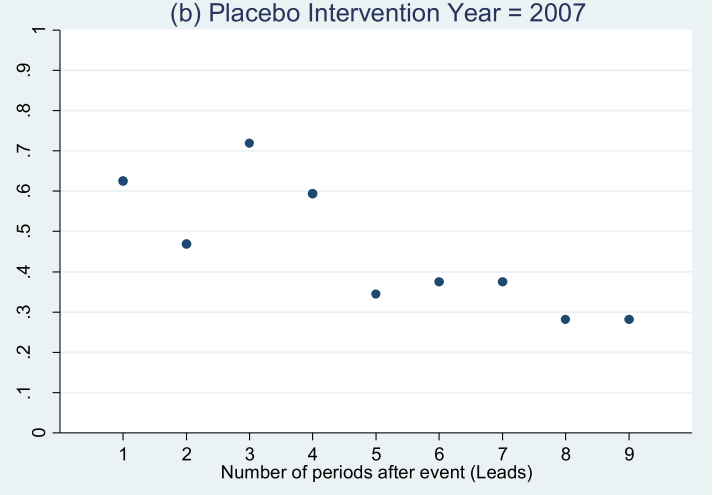

Fig. 9 Assignment of false trans fat policy year. A Synthetic control estimates. (a) 1997 as placebo intervention year (RMSE $=0.06)$. (b) 2007 placebo intervention year (RMSE $=0.27$. B Randomization inference. (a) Placebo intervention year $=1997$. (b) Placebo intervention year $=2007$

rate above the observed rate in the post-2007 period. Note that the synthetic Denmark before 2007 fails to adequately capture the CVD death rate of the actual Denmark for the entire pre-2007 period. Hence, the relatively weak balance between the CVD death rate covariates suggests that synthetic Denmark fails to provide a reasonable approximation to the CVDrelated mortality rate in the absence of the 2007 antismoking legislation. We interpret these results as further evidence that the counterfactual outcome is driven by the de facto TFA policy intervention in 2001 rather than by any voluntary TFA consumption drop in response to the report or by the anti-smoking legislation. Furthermore, in panel (b), we compute the pseudo $p$ values to determine whether the estimated post-treatment effects for both placebo years are driven by chance. Notice that pre-intervention RMSE is very similar to the baseline result on CVD mortality in Fig. 1. We find that the $p$ values on whether the effects are obtained at random are in the range between 9 and $15 \%$ in the full post-intervention period, respectively. In the last year of the intervention period, the $p$ value of 1997 placebo year is 50\% $(=0.093 / 0.062)$ higher than the $p$ value of the true policy treatment year, which shows that the mortality effect of the placebo years is much weaker than the effect of the intervention in the true year. Given that the covariates and past levels of mortality seem to adequately capture pre-TFA parallel trends with little discrepancy in pre-intervention RMSE, we interpret this as the evidence of the relatively weak effect of the placebo year. Figure 10 depicts the intertemporal $p$ values on the 1997 and 2007 placebo years along with the baseline $p$ values for the mortality effect of the true policy year. The evidence readily suggests that the true year of TFA policy yields the lowest simulation-based pseudo $p$ values on whether the effects are obtained at random. In the fifteenth year after intervention, the $p$ value for the 1997 placebo year is twice $(=0.125 / 0.062)$ the size of the $p$ value of 


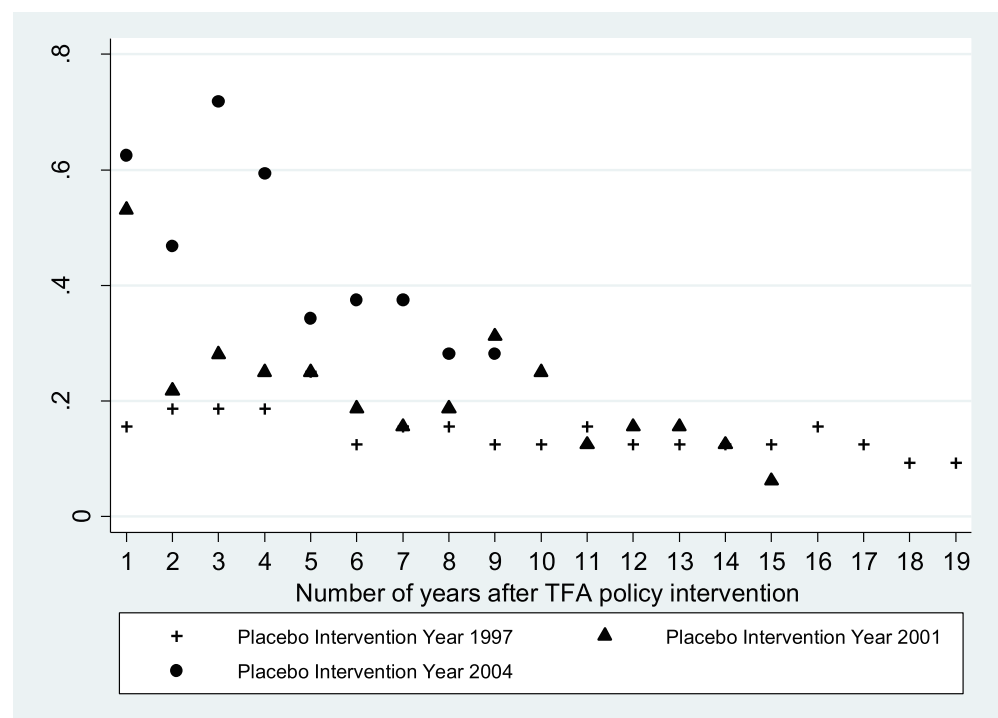

Fig. 10 Randomization inference on the falsely assigned years of trans fat policy

the true year, which further confirms a reasonably weak effect of the placebo years.

We extend the randomization inference with the 1997 placebo year to all other public health outcomes affected by the ban. Figure 11 presents the intertemporal distribution of $p$ values for the full set of obesity rates as well as fraction of overweight and BMI variables. The evidence indicates particularly weak effects of the reassigned TFA intervention to the year 1997 on the all public health outcomes. The $p$ values for the adolescent obesity rate are in the range between 0.45 and 0.99 for the entire post-intervention period, which confirms that the 1997 placebo effects are most likely driven by chance. A similar pattern is prevalent for the adult and child obesity rates, and for the fraction of overweight. Lastly, we also compute the $p$ value for the body mass index that could arguably be affected by the 1997 quasi-policy treatment posited by the release of the report by Danish Nutrition Council. The resulting $p$ values from the placebo runs tend to increase over time and exceed 0.9 threshold by the end of the post-intervention period. The $p$ values from the 1997 placebo year clearly suggest that the effects are likely obtained at random.

\subsubsection{Sensitivity to country-level weights}

Our fourth robustness check is to assess the synthetic control group's internal validity by excluding countries with the largest weight share from the donor pool. This allows us to determine whether the counterfactual outcomes are robust to a change in the country sets that form synthetic Denmark, and whether these outcomes remain stable. We adopt a lenient cutoff and exclude countries whose weight in the synthetic Denmark represents more than $10 \%$ of the total from the donor pool.

In Fig. 12, we reproduce the results based on the alternative set of countries forming synthetic Denmark for all respective outcome variables. The composition of the synthetic control groups for Denmark without the key original donors shows the reproduced synthetic control estimates for the CVD death rate. Since both Australia and Finland account for more than a 10\%-weight share, both countries were excluded from the donor pool in forming an alternative synthetic Denmark. The reproduced results suggest the estimated TFA policy intervention impact remains stable in terms of both the magnitude and direction of the counterfactual CVD death rate after 2001. The trajectory of Denmark's CVD mortality prior to 2001 is best described by a linear combination of the UK (83\%) and the Netherlands (17\%). The reproduced estimates have a pre-2001 RMSE almost identical to that obtained in Fig. 1, adding strength to our conclusion on the benefits of the TFA policy intervention for CVD mortality.

Panel (b) reports the re-estimated TFA ban effects on the adult obesity rate. The evidence confirms our prior estimates and suggests the policy intervention did not substantially affect the adult obesity rate. In particular, the adult obesity rate of synthetic Denmark is almost identical to actual Denmark before and after the 2001 policy intervention. By excluding Belgium and Germany from the donor pool, the adult obesity rate of synthetic Denmark in the pre-2001 period is 


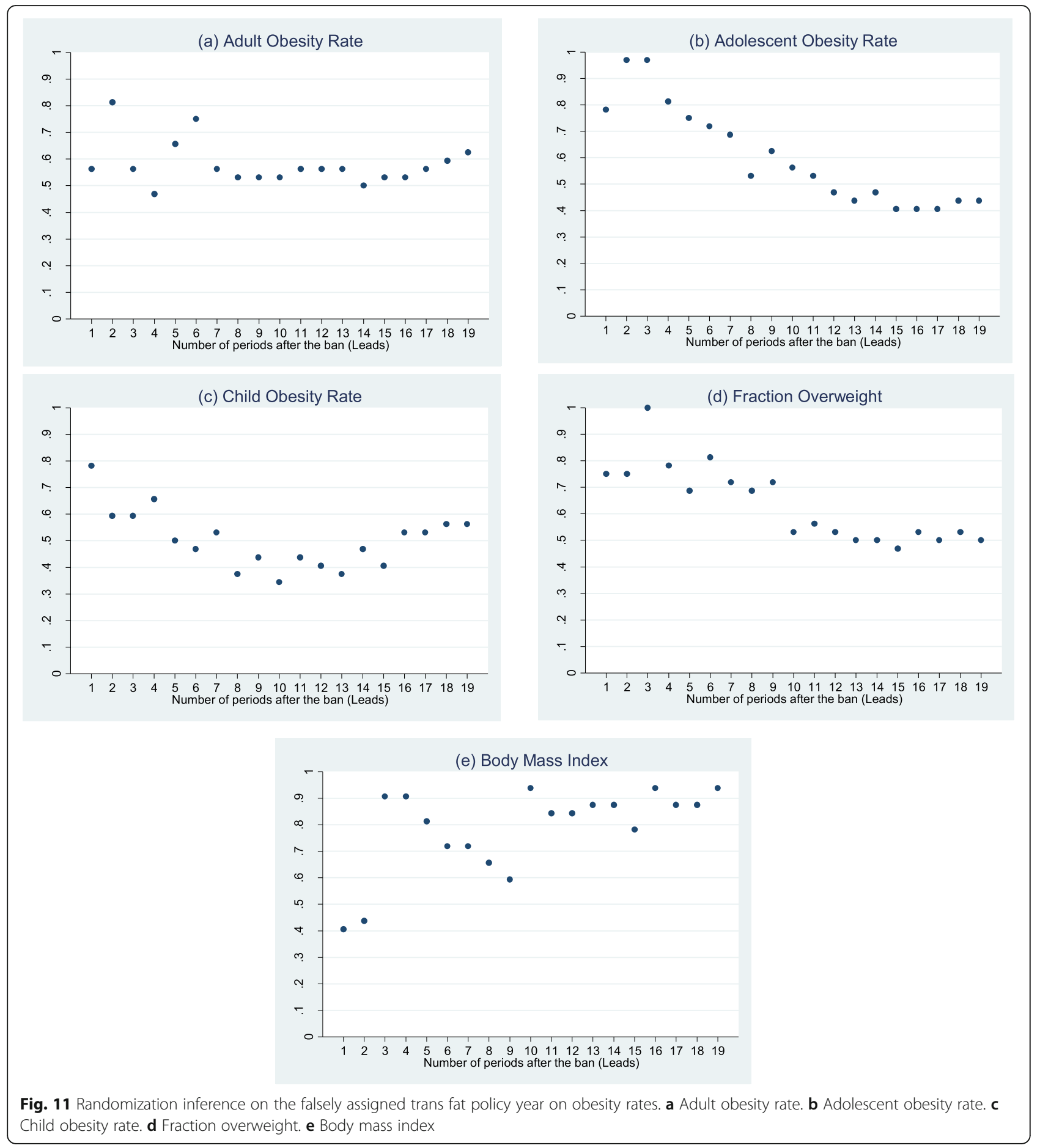

best captured by the weighted average of past obesity rate and covariates of France (46\%), Italy (33\%), the USA (12\%), Japan (8\%), and the Netherlands (2\%). For the adolescent and child obesity rates, the reproduced estimates indicate a sizeable difference between actual Denmark and synthetic Denmark in the post2001 period. The obesity rate in the former is considerably higher compared to actual Denmark. By excluding Belgium and Japan, the counterfactual outcome appears to be driven by the pre-2001 trends. We partially mitigate this concern by running a randomization inference similar to Fig. 4, which suggests the probability the effect is obtained by chance is below $5 \%$.

Note that in Table 5, Belgium and Japan have a disproportionately large weight share in synthetic 
(a) Excluded Sets: Australia and Finland

(a) CVD death rate

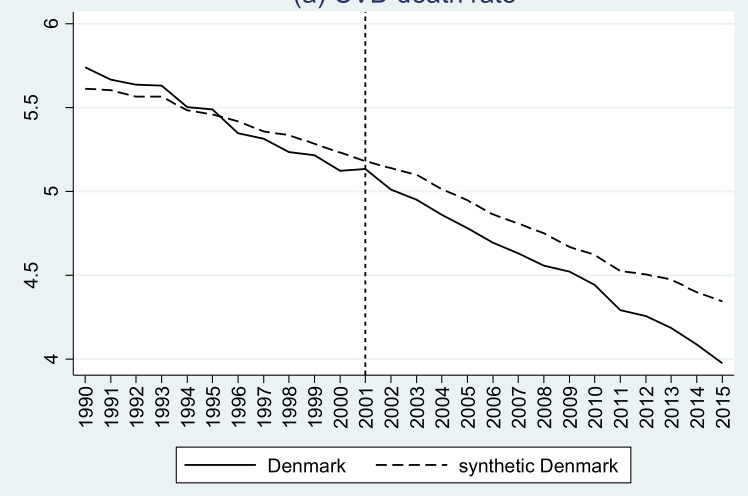

(c) Excluded Sets: Belgium and Japan

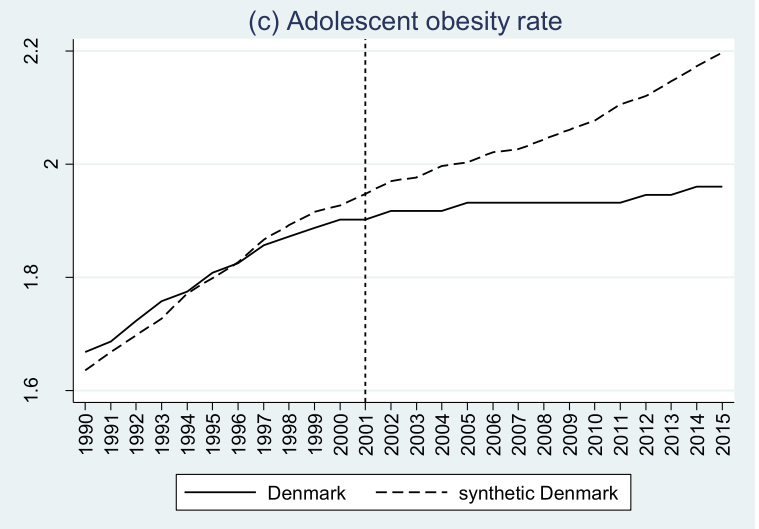

(e) Excluded Sets: Germany

(e) Fraction overweight

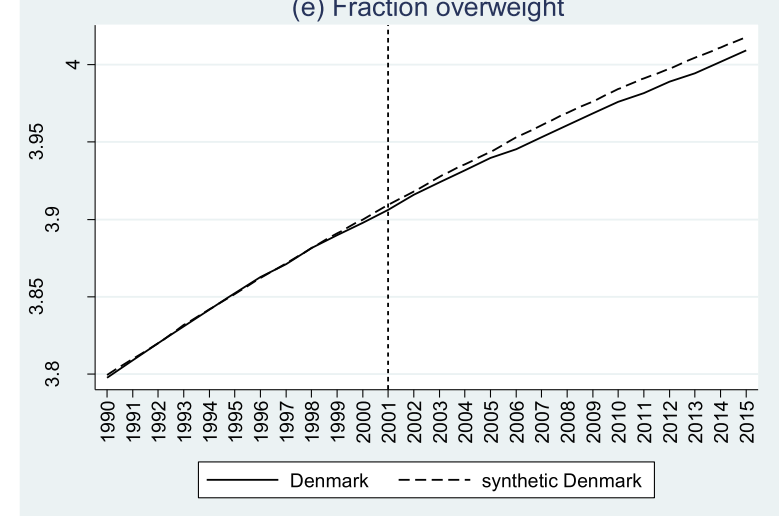

(b) Excluded Sets: Belgium and Germany

(b) Adult obesity rate

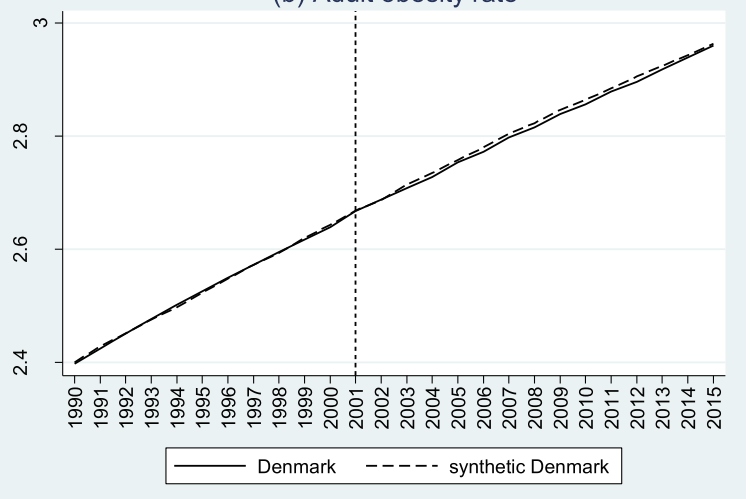

(d) Excluded Sets: Belgium and Japan

(d) Child obesity rate

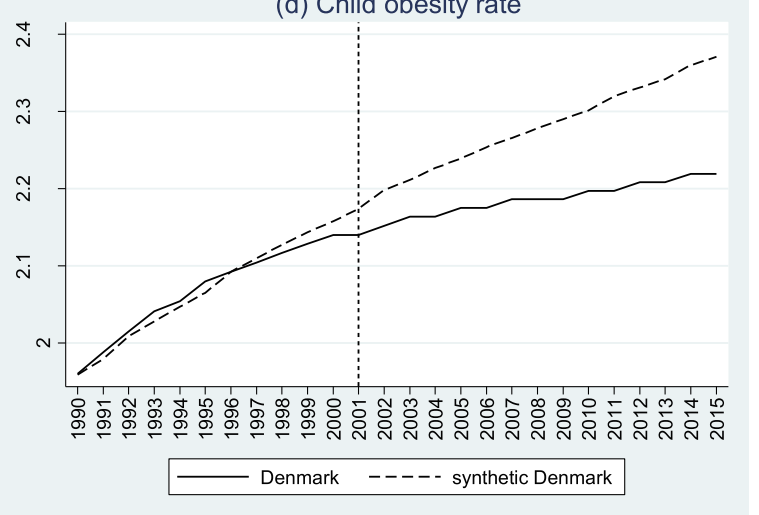

(f) Excluded Sets: Belgium

(f) Body mass index

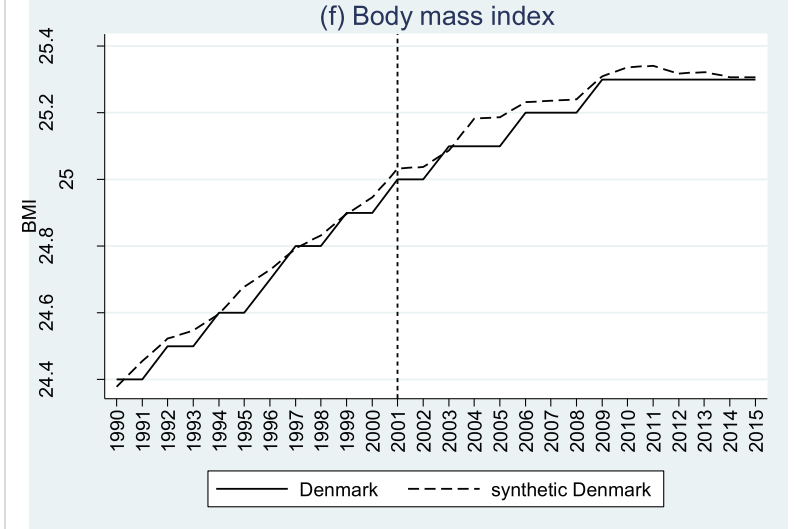

Fig. 12 Effects of Denmark's trans fat ban on cardiovascular death rates and obesity with alternative synthetic control groups. a Excluded sets: Australia and Finland; CVD death rate. b Excluded sets: Belgium and Germany; adult obesity rate. c Excluded sets: Belgium and Japan; adolescent obesity rate. $\mathbf{d}$ Excluded sets: Belgium and Japan; child obesity rate. e Excluded sets: Germany; fraction overweight. Excluded sets: Belgium; body mass index

Denmark, indicating that both countries adequately capture the pre-2001 adolescent and child obesity levels very well. Hence, pre-existing trends in the adolescent and child obesity rates are not surprising. For the adolescent obesity rate, Sweden (68\%) and the USA (23\%) have the highest weight share in the 
Table $\mathbf{5}$ Composition of synthetic control groups for Denmark with alternative country sets

\begin{tabular}{|c|c|c|c|c|c|c|}
\hline & $\begin{array}{l}\text { Cardiovascular disease death } \\
\text { rate }\end{array}$ & $\begin{array}{l}\text { Adult obesity } \\
\text { rate }\end{array}$ & $\begin{array}{l}\text { Adolescent obesity } \\
\text { rate }\end{array}$ & $\begin{array}{l}\text { Child obesity } \\
\text { rate }\end{array}$ & $\begin{array}{l}\text { Fraction } \\
\text { overweight }\end{array}$ & $\begin{array}{l}\text { Body mass } \\
\text { index }\end{array}$ \\
\hline RMSE & 0.076 & 0.002 & 0.021 & 0.01 & 0.001 & 0.032 \\
\hline Australia & 0 & 0 & 0.002 & 0 & 0.08 & 0 \\
\hline Austria & - & - & - & - & - & - \\
\hline Belgium & 0 & 0 & 0 & 0 & 0 & 0 \\
\hline Brazil & 0 & 0 & 0 & 0 & 0 & 0 \\
\hline Canada & 0 & 0 & 0 & 0 & 0 & 0.18 \\
\hline Chile & 0 & 0 & 0 & 0 & 0 & 0 \\
\hline Colombia & 0 & 0 & 0 & 0 & 0 & 0 \\
\hline Costa Rica & 0 & 0 & 0 & 0 & 0 & 0 \\
\hline Czechia & 0 & 0 & 0 & 0 & 0 & 0 \\
\hline Estonia & 0 & 0 & 0 & 0 & 0.13 & 0 \\
\hline Finland & 0 & 0 & 0.02 & 0.001 & 0.50 & 0.07 \\
\hline France & 0 & 0.46 & 0 & 0 & 0 & 0.37 \\
\hline Germany & 0 & 0 & 0 & 0.05 & 0 & 0 \\
\hline Greece & 0 & 0 & 0 & 0 & 0 & 0 \\
\hline Hungary & - & - & - & - & - & - \\
\hline Iceland & - & - & - & - & - & - \\
\hline Ireland & 0 & 0 & 0 & 0 & 0 & 0 \\
\hline Israel & 0 & 0 & 0 & 0.34 & 0 & 0 \\
\hline Italy & 0 & 0.33 & 0.06 & 0.08 & 0 & 0.11 \\
\hline Japan & 0 & 0.08 & 0 & 0 & 0.07 & 0 \\
\hline Latvia & 0 & 0 & 0 & 0 & 0 & 0 \\
\hline Lithuania & 0 & 0 & 0 & 0 & 0 & 0 \\
\hline Mexico & 0 & 0 & 0 & 0 & 0 & 0 \\
\hline Netherlands & 0.17 & 0.02 & 0 & 0 & 0 & 0 \\
\hline $\begin{array}{l}\text { New } \\
\text { Zealand }\end{array}$ & 0 & 0 & 0 & 0 & 0 & 0 \\
\hline Norway & - & - & - & - & - & - \\
\hline Poland & 0 & 0 & 0 & 0 & 0 & 0 \\
\hline Portugal & 0 & 0 & 0 & 0 & 0 & 0 \\
\hline Russia & 0 & 0 & 0 & 0 & 0 & 0 \\
\hline Slovakia & 0 & 0 & 0 & 0 & 0.02 & 0 \\
\hline Slovenia & 0 & 0 & 0 & 0 & 0 & 0 \\
\hline South Korea & 0 & 0 & 0 & 0 & 0 & 0.19 \\
\hline Sweden & 0 & 0 & 0.69 & 0.53 & 0.05 & 0.08 \\
\hline Switzerland & - & - & - & - & - & - \\
\hline UK & 0.83 & 0 & 0 & 0 & 0.03 & 0 \\
\hline USA & 0 & 0.12 & 0.23 & 0 & 0.12 & 0 \\
\hline
\end{tabular}

synthetic control group, while Sweden (53\%) and Israel (34\%) hold the largest shares in the control group for the child obesity rate prior to the TFA policy intervention in 2001. For the fraction of overweight, the reproduced synthetic control estimates confirm the baseline effect from Fig. 1. By excluding
Germany from the donor pool, the countries with the highest weights in the synthetic control group are France (37\%), Estonia (14\%), and the USA (12\%) along with a few others whose weight share is below $10 \%$. Notice that the composition of synthetic Denmark varies considerably across the outcome 
variables. The main underlying reasons for the difference in compositions are different comparative rank of Denmark in CVD death rate compared to obesity rates, as well as different means and standard deviations of the outcome variables, which, by default, imply that the composition of synthetic Denmark cannot be the same across all outcome variables considered in this investigation as shown in Table 2 and Table 3.

\subsubsection{Effects of the trans fat ban in other countries}

Our final robustness check is to validate our findings by estimating the effect of the similar ban in countries. Following Denmark's TFA policy intervention, several other countries introduced similar restrictions on the use of trans fats in the food supply. This then begs the question of whether the similar versions of the policy intervention applied outside Denmark are comparable in their outcomes as those we obtain for Denmark. In this sub-section, we estimate the TFA policy intervention's impact on the CVD death rate and obesity indicators for other countries with a sufficient post-treatment window, which includes Switzerland, Austria, and Iceland. To avoid an underpowered research design with too narrow a posttreatment estimation window, Norway and Hungary are excluded since they would yield only one posttreatment observation per outcome given they only introduced a TFA ban in 2014. For each treated country, other countries that passed a similar TFA policy intervention, including Denmark, are excluded from the donor pool to construct an internally consistent synthetic control group.

Table 6 reports the extended estimates of the TFA ban's impact on the CVD death rate and obesity rates for Switzerland, Austria, and Iceland. The evidence suggests that introduction of the ban in Switzerland produced a drop in the CVD death rate and a slowdown in the rising obesity. In stark contrast, the TFA policy intervention in Austria has had an unfavorable impact on obesity rates but no effect on CVD-related mortality. For Iceland, we find the TFA ban is associated with a substantial drop in mortality but also with the adverse effects on adolescent and child obesity. These findings are not surprising since implementation of the TFA ban in Switzerland is very similar to Denmark's de jure and de facto TFA policy. In contrast, the TFA ban passed by Austria leaves numerous products exempted from restricted use of trans fats given the weight requirement of the products subject to TFA regulation. The evidence on the impact of the ban in other countries clearly suggests that the TFA policy effect appears to be unique to the setting and intervention in Denmark whereas other countries do not follow the same post-intervention trends as Denmark.

Panel A reports the extended synthetic control estimates for all three countries. The evidence suggests that, in the 7 years since the TFA ban, the CVD death rate in Switzerland dropped by 5 deaths per 100,000 inhabitants with no evidence of the pre-2008 trends. The synthetic control group that best captures Switzerland's pre-2008 CVD mortality trajectory consists of Germany (52\%), Japan (26\%), the USA (13\%), Canada (10\%), and two others with a minor share of the weight. Moreover, the TFA ban further halted the adult and adolescent obesity trends by 0.8 and 0.2 of a percentage point, respectively, relative to the synthetic control group. The ban also reduced the prevalence of overweight by 0.6 of percentage point but had no effect on child obesity and BMI. Panel B reports the composition of synthetic Switzerland for each outcome in greater detail. In Appendix 1, we present the full set of figures displaying the TFA ban's effects in Switzerland.

The effects of Austria's TFA policy intervention in 2009 differ markedly from the effects found for Switzerland and Denmark. While the TFA ban arguably had no effect on CVD mortality, obesity rates rose considerably after the policy intervention. In particular, our estimates suggest the obesity rate increased between 0.2 and 0.3 of a percentage point, respectively, in response to the TFA policy intervention relative to the synthetic control group. Countries with the highest weight share in synthetic Austria are Belgium (18\%) for the adult obesity rate, France $(40 \%)$ for the adolescent obesity rate, and the Netherlands for the child obesity rate $(50 \%)$, respectively. In Appendix 2, we provide the full set of synthetic control figures for Austria.

Finally, the effects of the TFA policy intervention in Iceland in 2011 suggest the TFA ban had a favorable impact on CVD-related mortality, yet adversely affected obesity rates (Appendix 3). In particular, our estimates indicate the CVD death rate decreased by 6 deaths per 100,000 inhabitants in response to the TFA policy intervention in 2011. The magnitude of the estimate is comparable to the effects obtained for Switzerland. The set of countries that best approximate Iceland's CVD mortality trend before 2011 comprises Sweden (46\%), Ireland (30\%), Costa Rica (13\%), Mexico (10\%), and Brazil (0.1\%). Given Iceland's relatively high CVD death rate and high per capita income level, the synthetic control group's composition is not surprising. Unlike the results for Denmark, our findings show the TFA ban in Iceland is not associated with a drop in childhood and adolescent obesity rates. The estimates suggest that in the post-TFA ban 
Table 6 Impact of the TFA ban on public health outcomes outside Denmark

\begin{tabular}{|c|c|c|c|c|c|c|c|}
\hline & $\begin{array}{l}\text { Year of the } \\
\text { ban }\end{array}$ & CVD death rate & $\begin{array}{l}\text { Adult obesity } \\
\text { rate }\end{array}$ & $\begin{array}{l}\text { Adolescent obesity } \\
\text { rate }\end{array}$ & $\begin{array}{l}\text { Child obesity } \\
\text { rate }\end{array}$ & $\begin{array}{l}\text { Fraction } \\
\text { overweight }\end{array}$ & BMI \\
\hline \multicolumn{8}{|c|}{ Panel A: synthetic control estimates } \\
\hline Switzerland & 2008 & $\begin{array}{l}5 \text { fewer deaths per } 100,000 \\
(0.022)\end{array}$ & $\begin{array}{l}-0.8 \\
\text { p.p.(0.017) }\end{array}$ & - 0.2 p.p. $(0.027)$ & No effect & - 0.6 p.p.(0.005) & No effect \\
\hline Austria & 2009 & No effect & $\begin{array}{l}+0.2 \\
\text { p.p.(0.002) }\end{array}$ & + 0.25 p.p. $(0.005)$ & $\begin{array}{l}+0.30 \\
\text { p.p.(0.004) }\end{array}$ & No effect & $\begin{array}{l}+0.08 \\
\text { b.p. }(0.027)\end{array}$ \\
\hline Iceland & 2011 & $\begin{array}{l}6 \text { fewer deaths per } 100,000 \\
(0.047)\end{array}$ & No effect & + 0.32 p.p. $(0.003)$ & $\begin{array}{l}+0.32 \\
\text { p.p.(0.003) }\end{array}$ & $\begin{array}{l}-0.3 \\
\text { p.p.(0.0005) }\end{array}$ & $\begin{array}{l}+0.13 \\
\text { b.p.(0.033) }\end{array}$ \\
\hline
\end{tabular}

Panel B: composition of the synthetic control group for Switzerland

\begin{tabular}{|c|c|c|c|c|c|}
\hline Belgium & 0.002 & 0 & 0 & 0 & 0 \\
\hline Brazil & 0.002 & 0 & 0 & 0 & 0 \\
\hline Canada & 0.098 & 0 & 0 & 0.037 & 0 \\
\hline Colombia & 0 & 0 & 0 & 0.037 & 0 \\
\hline Finland & 0 & 0 & 0 & 0 & 0.66 \\
\hline Germany & 0.512 & 0.058 & 0 & 0 & 0 \\
\hline Japan & 0.255 & 0.131 & 0.207 & 0.489 & 0.117 \\
\hline Netherlands & 0 & 0 & 0.426 & 0.437 & 0 \\
\hline Sweden & 0 & 0.474 & 0.367 & 0 & 0 \\
\hline USA & 0.132 & 0.337 & 0 & 0 & 0.227 \\
\hline
\end{tabular}

Panel C: composition of the synthetic control group for Austria

\begin{tabular}{|c|c|c|c|c|c|c|}
\hline Australia & 0 & 0.039 & 0 & 0.019 & 0 & 0 \\
\hline Belgium & 0.225 & 0.181 & 0.072 & 0.218 & 0.361 & 0.176 \\
\hline Canada & 0 & 0 & 0 & 0 & 0.108 & 0 \\
\hline Estonia & 0 & 0 & 0 & 0 & 0 & 0.011 \\
\hline Finland & 0.445 & 0.01 & 0.162 & 0 & 0 & 0 \\
\hline France & 0 & 0 & 0.541 & 0.017 & 0 & 0.317 \\
\hline Germany & 0.071 & 0.146 & 0 & 0.173 & 0.071 & 0.004 \\
\hline Greece & 0 & 0.005 & 0 & 0 & 0 & 0 \\
\hline Italy & 0.026 & 0.159 & 0 & 0.094 & 0.166 & 0.010 \\
\hline Japan & 0 & 0.044 & 0 & 0.050 & 0.050 & 0.059 \\
\hline Latvia & 0 & 0 & 0 & 0.001 & 0 & 0 \\
\hline Lithuania & 0.032 & 0 & 0 & 0 & 0 & 0 \\
\hline Netherlands & 0 & 0.138 & 0.154 & 0.408 & 0.015 & 0.276 \\
\hline South Korea & 0 & 0.037 & 0 & 0 & 0.106 & 0.055 \\
\hline Sweden & 0 & 0.141 & 0 & 0 & 0 & 0 \\
\hline UK & 0 & 0 & 0.047 & 0 & 0 & 0.044 \\
\hline USA & 0.20 & 0.10 & 0.024 & 0.021 & 0.121 & 0.048 \\
\hline \multicolumn{7}{|c|}{ anel D: composition of the synthetic control group for Iceland } \\
\hline Belgium & 0 & 0 & 0.457 & 0.387 & 0.124 & 0 \\
\hline Brazil & 0.001 & 0 & 0 & 0.002 & 0 & 0 \\
\hline Canada & 0 & 0 & 0.014 & 0 & 0 & 0.081 \\
\hline Chile & 0 & 0.052 & 0 & 0 & 0 & 0 \\
\hline Costa Rica & 0.136 & 0 & 0 & 0 & 0 & 0 \\
\hline Estonia & 0 & 0.137 & 0 & 0 & 0.179 & 0 \\
\hline Finland & 0 & 0.143 & 0 & 0 & 0.385 & 0.257 \\
\hline
\end{tabular}


Table 6 Impact of the TFA ban on public health outcomes outside Denmark (Continued)

\begin{tabular}{|c|c|c|c|c|c|c|c|}
\hline & $\begin{array}{l}\text { Year of the } \\
\text { ban }\end{array}$ & CVD death rate & $\begin{array}{l}\text { Adult obesity } \\
\text { rate }\end{array}$ & $\begin{array}{l}\text { Adolescent obesity } \\
\text { rate }\end{array}$ & $\begin{array}{l}\text { Child obesity } \\
\text { rate }\end{array}$ & $\begin{array}{l}\text { Fraction } \\
\text { overweight }\end{array}$ & $\mathrm{BMl}$ \\
\hline France & & 0 & 0 & 0 & 0.004 & 0 & 0 \\
\hline Germany & & 0 & 0 & 0 & 0 & 0 & 0 \\
\hline Ireland & & 0.300 & 0.001 & 0 & 0 & 0 & 0 \\
\hline Israel & & 0 & 0.244 & 0.409 & 0.337 & 0.08 & 0.164 \\
\hline Italy & & 0 & 0 & 0 & 0.178 & 0 & 0 \\
\hline Japan & & 0 & 0 & 0 & 0.027 & 0 & 0 \\
\hline Latvia & & 0 & 0 & 0 & 0 & 0.059 & 0 \\
\hline Netherlands & & 0 & 0.218 & 0.036 & 0 & 0 & 0.338 \\
\hline Mexico & & 0.099 & 0 & 0 & 0 & 0 & 0 \\
\hline Russia & & 0 & 0 & 0 & 0.005 & 0 & 0 \\
\hline South Korea & & 0 & 0.026 & 0 & 0 & 0 & 0 \\
\hline Spain & & 0 & 0.053 & 0 & 0 & 0 & 0 \\
\hline Sweden & & 0.465 & 0.125 & 0 & 0 & 0.043 & 0.160 \\
\hline UK & & 0 & 0 & 0 & 0 & 0 & 0 \\
\hline USA & & 0 & 0 & 0.084 & 0.059 & 0.129 & 0 \\
\hline
\end{tabular}

period there seems to be a rise in obesity rates for both age groups by 0.32 of a percentage point relative to the synthetic control group that best predicts Iceland's obesity trend prior to the policy intervention. Countries with the highest weight share in the synthetic control group for adolescent and child obesity rates are Belgium and Israel, respectively. On balance, the evidence clearly shows the TFA policy intervention in Switzerland had a favorable impact on CVD mortality and obesity rates while the policy intervention in Iceland had a beneficial effect on CVD mortality only but, at the same time, seems to be associated with rising obesity rates. By contrast, the TFA ban in Austria failed to translate into a lower CVD death rate and had a negative impact on obesity rates across all age cohorts. Given the marked institutional differences in the TFA ban among the three countries, the contrasting effects with respect to the obesity rates are no surprise.

In Fig. 13, we replicate the randomization inference from section 5.3.1, conduct an "in-space" placebo check with false policy reassignment to the full set of

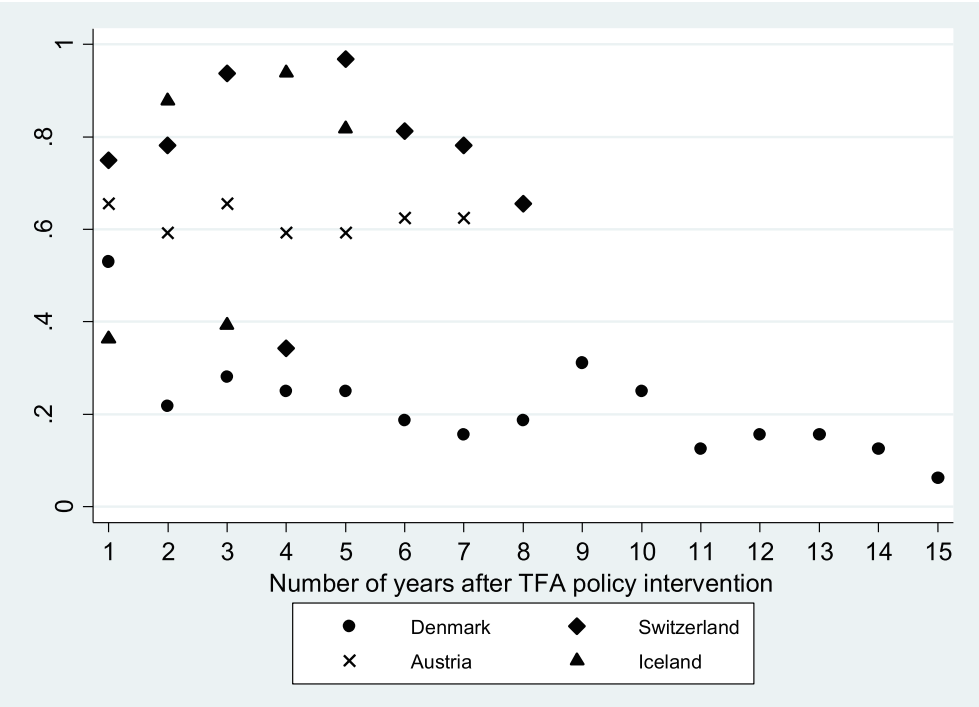

Fig. 13 Randomization inference on the mortality effect of TFA ban in other countries 
untreated countries, and obtain the probabilities that the TFA mortality effect is obtained at random. The evidence highlights clearly perceptible downward trends in the probability for Denmark in contrast to stationary distribution of $p$ values in Switzerland, Iceland, and Austria. Not a single country approaches the $p$ value of Denmark's policy intervention in the post-intervention period, which confirms the notion that the effect of the TFA ban is specific to Denmark.

\subsection{Possible limitations}

We should recognize that our approach does not disentangle the causal effect of the TFA policy intervention because numerous other social, economic, and demographic variables might jointly influence the trends of CVD mortality and obesity rates. Our synthetic control estimates highlight evidence showing that CVD death rates dropped considerably in response to the TFA policy intervention, which resulted in de facto anticipation of the ban in 2001 and the de jure legislated ban in 2003. In addition, the rates of child and adolescent obesity slowed down in response to the policy intervention relative to Denmark's synthetic control group. Another limitation of our study concerns the effectiveness of other potential regulatory policies, as aspect that still awaits conclusive empirical analysis. Designated regulatory policy alternatives to the TFA ban include, but are not limited to, the taxation of TFA-saturated products, a public campaign against the industrial use and private consumption of TFAs, educational efforts, product labeling, and voluntary policies aimed at discouraging TFA use. This study does not address the effectiveness of these policy alternatives and their impact on public health outcomes, which may deserve more attention in future empirical research. Nevertheless, our synthetic control estimates hinge on the parallel trend assumption and provide some evidence of the benefits of the TFA ban for public health compared to countries not introducing such an TFA intervention during the time period covered by our investigation. To assess whether the TFA ban is a superior form of regulatory intervention, a comparative study with other regulatory options as policy treatment variables would be necessary.

\section{Conclusion}

In this paper, we examine the effects of the trans fat ban on the cardiovascular (CVD) death rate and obesity rates for a sample of 38 countries in the period 1990-2016. To this end, we consider the de facto anticipation of the TFA ban in Denmark in 2001 and estimate the effect of the policy intervention on cardiovascular mortality and several obesity indicators.
We rely on parallel trends in the full set of past health outcomes and covariates prior to the policy intervention, and compute the missing counterfactual scenario in the hypothetical absence of the policy intervention. Using a large set of covariates, we compute a synthetic Denmark as a linear combination of other countries' covariates and past outcomes that follow similar health trends as the actual Denmark prior to the 2001 policy intervention.

Our estimates highlight substantial public health benefits accrue from banning trans fats. In particular, the synthetic control estimates imply that by 2016 CVD mortality had decreased by 30 fewer deaths per 100,000 inhabitants relative to the synthetic control group. Our findings also suggest the TFA policy intervention helped mitigate the trend of rising obesity. Moreover, our estimates imply the TFA policy intervention's effects are especially large for adolescent obesity and moderate for child obesity, whereas the effects on adult obesity are indistinguishable from zero. The results clearly suggest that the effect of the TFA policy intervention is associated with a beneficial long-run effect whereas the shortrun effects are rather weak, which confirms our theoretical notions of a moderate beneficial effect of the TFA policy intervention in Denmark.

We perform a series of robustness checks and compute a battery of placebo distributions to further unpack the effects of the TFA policy intervention. We show the effects of Denmark's TFA policy on CVD mortality and youth obesity rates do not seem to be due to chance. By deliberately assigning TFA policy to wrong dates and other countries, we show the effect of the 2001 TFA policy intervention is specific to Denmark and does not appear to be driven by alternative dates; namely, by release of the first official trans fat report by the Danish Nutrition Council (in 1997) and by the anti-smoking legislation (in 2007). We also show the TFA policy's effects are specific to the CVD death rate and obesity rates, while, simultaneously, the policy effects on health outcomes not related to the TFA consumption are weak.

The key policy implication of our research is that a TFA policy intervention banning trans fats is an effective remedy for the negative externalities that arise from the consumption of trans fats and hold negative labor market and human capital implications. The ban also appears to be an effective low-cost answer to the burden of high obesity rates and widespread cardiovascular diseases, both of which impose high welfare and longevity costs. Our study addresses the ban's effect on public health outcomes whereas the ban's effects on sales of products containing multiple components and sales of substitutes were not considered in this work and call for careful attention in future research. 


\section{Appendix 1}

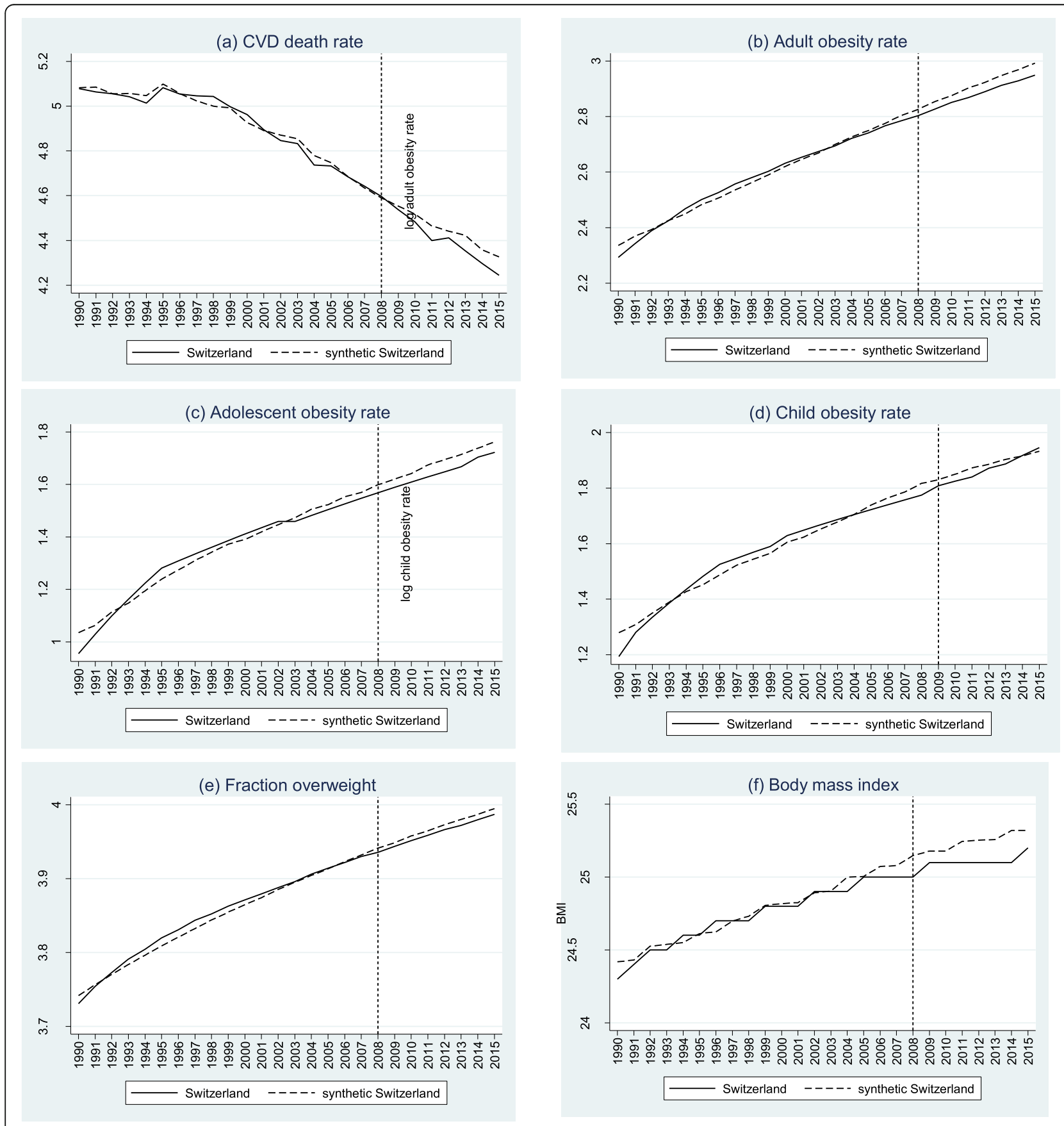

Fig. 14 Synthetic control estimates of the trans fats ban in Switzerland. a CVD death rate. b Adult obesity rate. c Adolescent obesity rate. $\mathbf{d}$ Child obesity rate. e Fraction overweight. $\mathbf{f}$ Body mass index 


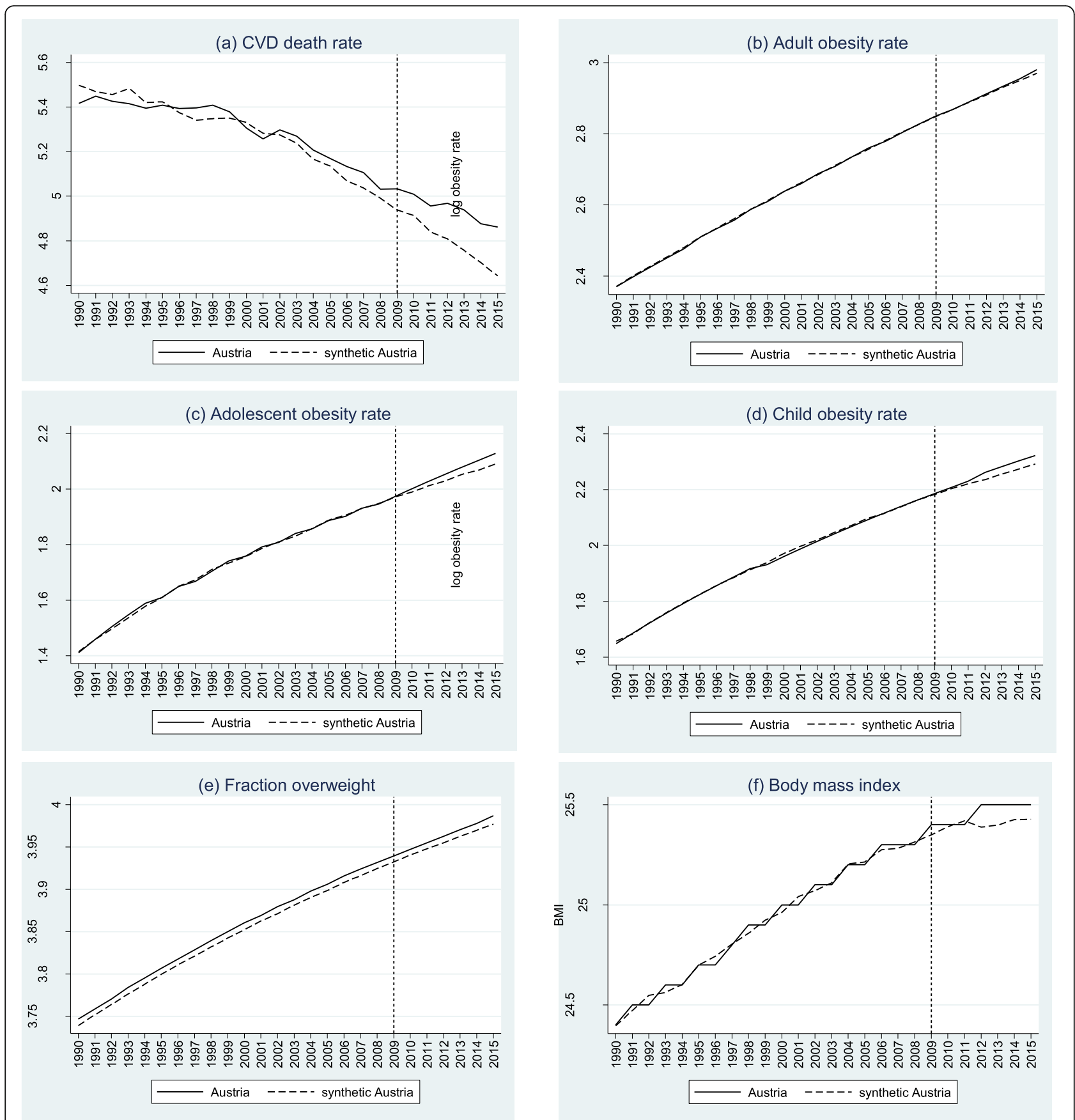

Fig. 15 Synthetic control estimates of the trans fats ban in Austria. a CVD death rate. b Adult obesity rate. c Adolescent obesity rate. $\mathbf{d}$ Child obesity rate. e Fraction overweight. $\mathbf{f}$ Body mass index 


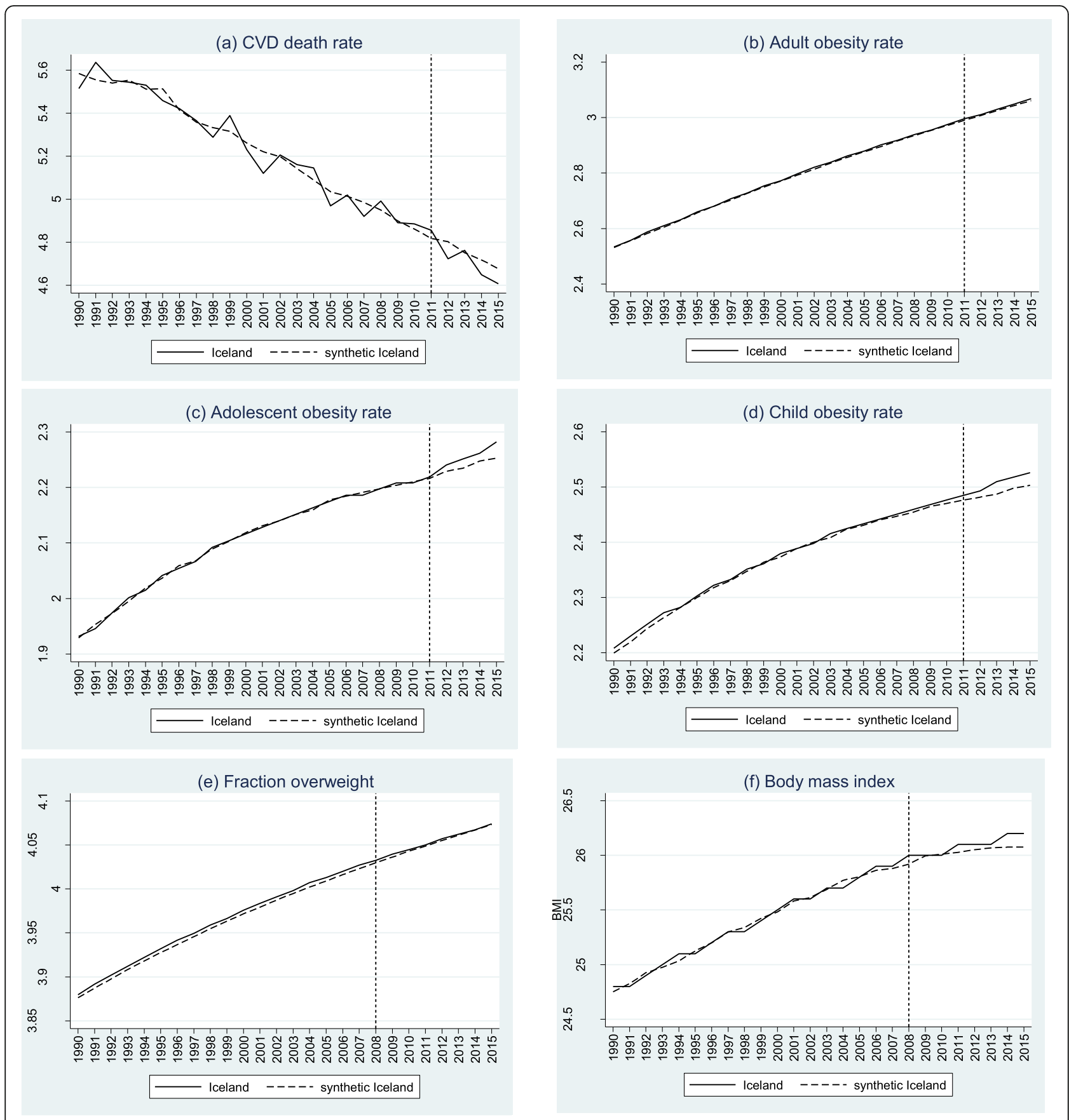

Fig. 16 Synthetic control estimates of the trans fat ban in Iceland. a CVD death rate. b Adult obesity rate. c Adolescent obesity rate. $\mathbf{d}$ Child obesity rate. e Fraction overweight. $\mathbf{f}$ Body mass index 


\section{Acknowledgements}

The authors would like to thank Rafael Lalive for his excellent editorial guidance, two anonymous referees for their constructive suggestions and critiques which improved the content and language of the manuscript, Boudewijn Bouckaert (University of Ghent), Gerrit De Geest (Washington University, St. Louis), Ben Depoorter (University of California, Hastings), Miguel Garcia Posada-Gomez (Bank of Spain), Nuno Garoupa (George Mason University), Sven Hoeppner (University of Ghent), Jonathan Klick (University of Pennsylvania), Lela Mélon (Universitat Pompeu Fabra), Edward Norton (University of Michigan), Juan S. Mora-Sanguinetti (Bank of Spain), Hélène Schernberg (ETH Zürich), Stefan Voigt (University of Hamburg), Peter Van Wijck (Leiden University), and Wolfgang Weigel (University of Vienna), as well as the various participants of the $16^{\text {th }}$ Annual German Law and Economics Conference (Ljubljana), the $8^{\text {th }}$ Annual Conference of Spanish Law and Economics Association (Madrid), and the EMLE Midterm Law and Economics Meeting (Ghent), for their comments, feedback, initiatives, and suggestions.

\section{Authors' contributions}

Both authors contributed to all parts of this paper on an equal level. RS mainly analyzed the trans fat ban's effects on health outcomes using the synthetic control methodology. MK mainly discussed and analyzed the legal and institutional background of the trans fat policy. Both authors read and approved the final manuscript.

\section{Funding}

No funds were received for this study.

\section{Availability of data and materials}

For replication and research transparency purposes the dataset will be uploaded to the online repository (i.e., Harvard Dataverse) along with the full statistical code.

\section{Competing interests}

The authors declare that they have no competing interests.

\section{Received: 13 September 2018 Accepted: 29 October 2019}

Published online: 03 March 2020

\section{References}

Abadie, A., Diamond, A., \& Hainmueller, J. (2010). Synthetic control methods for comparative case studies: estimating the effect of California's tobacco control program. Journal of the American Statistical Association, 105(490), 493-505.

Abadie, A., Diamond, A., \& Hainmueller, J. (2015). Comparative politics and the synthetic control method. American Journal of Political Science, 59(2), 495-510.

Abadie, A., \& Gardeazabal, J. (2003). The economic costs of conflict: a case study of the Basque Country. American Economic Review, 93(1), 113-132.

Acemoglu, D., Johnson, S., Kermani, A., Kwak, J., \& Mitton, T. (2016). The value of connections in turbulent times: evidence from the United States. Journal of Financial Economics, 121(2), 368-391.

Allen, K., Pearson-Stuttard, J., Hooton, W., Diggle, P., Capewell, S., \& O'Flaherty, M. (2015). Potential of trans fats policies to reduce socioeconomic inequalities in mortality from coronary heart disease in England: cost effectiveness modelling study. British Medical Journal, 351, 4583.

Anderson, P. M., Butcher, K. F., \& Levine, P. B. (2003). Maternal employment and overweight children. Journal of Health Economics, 22(3), 477-504.

Ascherio, A., Hennekens, C. H., Buring, J. E., Master, C., Stampfer, M. J., \& Willett, W. C. (1994). Trans-fatty acids intake and risk of myocardial infarction. Circulation, 89(1), 94-101.

Astrup, A., Dyerberg, J., Selleck, M., \& Stender, S. (2008). Nutrition transition and its relationship to the development of obesity and related chronic diseases. Obesity Reviews, 9, 48-52.

Auld, M. C., \& Powell, L. M. (2009). Economics of food energy density and adolescent body weight. Economica, 76(304), 719-740.

Baer, D. J., Judd, J. T., Clevidence, B. A., \& Tracy, R. P. (2004). Dietary fatty acids affect plasma markers of inflammation in healthy men fed controlled diets: a randomized crossover study. The American Journal of Clinical Nutrition, 79(6), 969-973.

Bech-Larsen, T., \& Aschemann-Witzel, J. (2012). A macromarketing perspective on food safety regulation: the Danish ban on trans-fatty acids. Journal of Macromarketing, 32(2), 208-219.
Bertrand, M., Duflo, E., \& Mullainathan, S. (2004). How much should we trust differences-in-differences estimates? The Quarterly Journal of Economics, 119(1), 249-275.

Billmeier, A., \& Nannicini, T. (2013). Assessing economic liberalization episodes: a synthetic control approach. Review of Economics and Statistics, 95(3), 983-1001.

Brouwer, I. A., Wanders, A. J., \& Katan, M. B. (2013). Trans fatty acids and cardiovascular health: research completed? European Journal of Clinical Nutrition, 67(5), 541-547.

Cantor, J., Torres, A., Abrams, C., \& Elbel, B. (2015). Five years later: awareness of New York City's calorie labels declined, with no changes in calories purchased. Health Affairs, 34(11), 1893-1900.

Cavallo, E., Galiani, S., Noy, I., \& Pantano, J. (2013). Catastrophic natural disasters and economic growth. Review of Economics and Statistics, 95(5), 1549-1561.

Cawley, J. (2004). The impact of obesity on wages. Journal of Human Resources, $39(2), 451-474$

Cawley, J. (2010). The economics of childhood obesity. Health Affairs, 29(3), 364-371.

Cawley, J., \& Liu, F. (2012). Maternal employment and childhood obesity: a search for mechanisms in time use data. Economics \& Human Biology, 10(4), 352-364.

Cawley, J., \& Meyerhoefer, C. (2012). The medical care costs of obesity: an instrumental variables approach. Journal of Health Economics, 31(1), 219-230.

Cawley, J., Moran, J., \& Simon, K. (2010). The impact of income on the weight of elderly Americans. Health Economics, 19(8), 979-993.

Cawley, J., Rizzo, J. A., \& Haas, K. (2007). Occupation-specific absenteeism costs associated with obesity and morbid obesity. Journal of Occupational and Environmental Medicine, 49(12), 1317-1324.

Cawley, J., \& Spiess, C. K. (2008). Obesity and skill attainment in early childhood. Economics \& Human Biology, 6(3), 388-397.

Chou, S. Y., Rashad, I., \& Grossman, M. (2008). Fast-food restaurant advertising on television and its influence on childhood obesity. The Journal of Law and Economics, 51(4), 599-618.

Cutler, D. M., Glaeser, E. L., \& Shapiro, J. M. (2003). Why have Americans become more obese? Journal of Economic Perspectives, 17(3), 93-118.

Dhar, T., \& Baylis, K. (2011). Fast-food consumption and the ban on advertising targeting children: the Quebec experience. Journal of Marketing Research, 48(5), 799-813.

Elbel, B., Gyamfi, J., \& Kersh, R. (2011). Child and adolescent fast-food choice and the influence of calorie labeling: a natural experiment. International Journal of Obesity, 35(4), 493-500.

Elbel, B., Kersh, R., Brescoll, V. L., \& Dixon, L. B. (2009). Calorie labeling and food choices: a first look at the effects on low-income people in New York City. Health Affairs, 28(6), 1110-1121.

Feenstra, R. C., Inklaar, R., \& Timmer, M. P. (2015). The next generation of the Penn World Table. American Economic Review, 105(10), 3150-3182.

Fertig, A., Glomm, G., \& Tchernis, R. (2009). The connection between maternal employment and childhood obesity: Inspecting the mechanisms. Review of Economics of the Household, 7(3), 227-255.

Finkelstein, E. A., Trogdon, J. G., Cohen, J. W., \& Dietz, W. (2009). Annual medical spending attributable to obesity: payer-and service-specific estimates. Health Affairs, 28(5), 822-831.

Galiani, S., \& Quistorff, B. (2017). The synth_runner package: utilities to automate synthetic control estimation using synth. The Stata Journal, 17(4), 834-849.

Gelbach, J. B., Klick, J., \& Stratmann, T. (2007). Cheap donuts and expensive broccoli: the effect of relative prices on obesity, Research Law Paper No. In 261, College of Law. Florida State: University.

Gobillon, L., \& Magnac, T. (2016). Regional policy evaluation: Interactive fixed effects and synthetic controls. Review of Economics and Statistics, 98(3), 535-551.

Gostin, L. O. (2007). Law as a tool to facilitate healthier lifestyles and prevent obesity. Journal of American Medical Association, 297(1), 87-90.

Harris, J. L., Bargh, J. A., \& Brownell, K. D. (2009). Priming effects of television food advertising on eating behavior. Health Psychology, 28(4), 404-413.

Hawkes, C. (2007). Regulating and litigating in the public interest: regulating food marketing to young people worldwide: trends and policy drivers. American Journal of Public Health, 97(11), 1962-1973.

Herbst, C. M., \& Tekin, E. (2011). Child care subsidies and childhood obesity. Review of Economics of the Household, 9(3), 349-378.

Kleven, H. J., Landais, C., \& Saez, E. (2013). Taxation and international migration of superstars: Evidence from the European football market. American Economic Review, 103(5), 1892-1924.

Klößner, S., Kaul, A., Pfeifer, G., \& Schieler, M. (2018). Comparative politics and the synthetic control method revisited: a note on Abadie et al. (2015). Swiss Journal of Economics and Statistics, 154(1), 1-11. 
Koletzko, B. (1992). Trans fatty acids may impair biosynthesis of long chain polyunsaturates and growth in man. Acta Paediatrica, 81(4), 302-306.

Komlos, J., \& Baur, M. (2004). From the tallest to (one of) the fattest: the enigmatic fate of the American population in the 20th century. Economics \& Human Biology, 2(1), 57-74.

Komlos, J., Smith, P. K., \& Bogin, B. (2004). Obesity and the rate of time preference: is there a connection? Journal of Biosocial Science, 36(2), 209-219.

Kortt, M. A., Langley, P. C., \& Cox, E. R. (1998). A review of cost-of-illness studies on obesity. Clinical Therapeutics, 20(4), 772-779.

Kovac, M., \& Spruk, R. (2019). Does the ban on trans-fats improve public health? In search of optimal policy response. Journal of Regulatory Economics, 55(3), 258-281.

Livingstone, S. (2006). Does TV advertising make children fat? Public Policy Research, 13(1), 54-61.

Lynn, R., \& Vanhanen, T. (2006). IQ and global inequality. Whitefish, MT: Washington Summit Publishers.

Missmer, S. A., Chavarro, J. E., Malspeis, S., Bertone-Johnson, E. R., Hornstein, M. D. Spiegelman, D., \& Hankinson, S. E. (2010). A prospective study of dietary fat consumption and endometriosis risk. Human Reproduction, 25(6), 1528-1535.

Mozaffarian, D., Katan, M. B., Ascherio, A., Stampfer, M. J., \& Willett, W. C. (2006). Trans fatty acids and cardiovascular disease. New England Journal of Medicine, 354(15), 1601-1613.

Naghavi, M., Abajobir, A. A., Abbafati, C., Abbas, K. M., Abd-Allah, F., Abera, S. F., \& Ahmadi, A. (2017). Global, regional, and national age-sex specific mortality for 264 causes of death, 1980-2016: a systematic analysis for the Global Burden of Disease Study 2016. The Lancet, 390(10100), 1151-1210.

Neumark, D., Salas, J. I., \& Wascher, W. (2014). Revisiting the minimum wage-employment debate: throwing out the baby with the bathwater? ILR Review, 67(Supp 3), 608-648.

Ng, M., Fleming, T., Robinson, M., Thomson, B., Graetz, N., Margono, C., \& Abraham, J. P. (2014). Global, regional, and national prevalence of overweight and obesity in children and adults during 1980-2013: a systematic analysis for the Global Burden of Disease Study 2013. The Lancet, 384(9945), 766-781.

Oh, K., Hu, F. B., Manson, J. E., Stampfer, M. J., \& Willett, W. C. (2005). Dietary fat intake and risk of coronary heart disease in women: 20 years of follow-up of the nurses' health study. American Journal of Epidemiology, 161(7), 672-679.

Onishi, N. (2008). Japan, seeking trim waists. measures millions. New York Times, (June 13).

Philipson, T. (2001). The world-wide growth in obesity: an economic research agenda. Health Economics, 10(1), 1-7.

Philipson, T. J., \& Posner, R. A. (2008). Is the obesity epidemic a public health problem? A review of Zoltan J. Acs and Alan Lyles's obesity, business and public policy. Journal of Economic Literature, 46(4), 974-982.

Powell, L. M. (2009). Fast food costs and adolescent body mass index: evidence from panel data. Journal of Health Economics, 28(5), 963-970.

Powell, L. M., \& Chaloupka, F. J. (2009). Food prices and obesity: evidence and policy implications for taxes and subsidies. The Milbank Quarterly, 87(1), 229-257.

Restrepo, B. J. (2017). Calorie labeling in chain restaurants and body weight: evidence from New York. Health Economics, 26(10), 1191-1209.

Restrepo, B. J., \& Rieger, M. (2016a). Denmark's policy on artificial trans fat and cardiovascular disease. American Journal of Preventive Medicine, 50(1), 69-76.

Restrepo, B. J., \& Rieger, M. (2016b). Trans fat and cardiovascular disease mortality: evidence from bans in restaurants in New York. Journal of Health Economics, 45, 176-196.

Schmeiser, M. D. (2009). Expanding wallets and waistlines: the impact of family income on the BMI of women and men eligible for the earned income tax credit. Health Economics, 18(11), 1277-1294.

Seale, J.L., Regmi, A \& J. Bernstein, J.M. (2003). International evidence on food consumption patterns, Technical Bulletin No. 1904, Economic Research Service, U.S. Department of Agriculture.

Serdula, M. K., Ivery, D., Coates, R. J., Freedman, D. S., Williamson, D. F., \& Byers, T. (1993). Do obese children become obese adults? A review of the literature. Preventive Medicine, 22(2), 167-177.

Sobal, J., \& Stunkard, A. J. (1989). Socioeconomic status and obesity: a review of the literature. Psychological Bulletin, 105(2), 260-275.

Stender, S., Dyerberg, J., \& Astrup, A. (2006). High levels of industrially produced trans fat in popular fast foods. New England Journal of Medicine, 354(15), $1650-1652$

Sturm, R., \& Datar, A. (2005). Body mass index in elementary school children, metropolitan area food prices and food outlet density. Public Health, 119(12), 1059-1068.
Teegala, S. M., Willett, W. C., \& Mozaffarian, D. (2009). Consumption and health effects of trans fatty acids: a review. Journal of AOAC International, 92(5), 1250-1257.

Thorpe, L. E., List, D. G., Marx, T., May, L., Helgerson, S. D., \& Frieden, T. R. (2004). Childhood obesity in New York City elementary school students. American Journal of Public Health, 94(9), 1496-1500.

Trasande, L., \& Chatterjee, S. (2009). The impact of obesity on health service utilization and costs in childhood. Obesity, 17(9), 1749-1754.

Trasande, L., Liu, Y., Fryer, G., \& Weitzman, M. (2009). Effects of childhood obesity on hospital care and costs, 1999-2005. Health Affairs, 28(4), 751-760.

Uauy, R., Aro, A., Clarke, R., L'abbé, M. R., Mozaffarian, D., Skeaff, C. M., \& Tavella, M. (2009). WHO Scientific Update on trans fatty acids: summary and conclusions. European Journal of Clinical Nutrition, 63(S2), S68.

Vadiveloo, M. K., Dixon, L. B., \& Elbel, B. (2011). Consumer purchasing patterns in response to calorie labeling legislation in New York City. International Journal of Behavioral Nutrition and Physical Activity, 8(1), 1111-1121.

Variyam, J. N., \& Cawley, J. (2006). Nutrition labels and obesity. Working Paper No. 11956, National Bureau of Economic Research.

Von Hinke Kessler Scholder, S. (2008). Maternal employment and overweight children: does timing matter? Health Economics, 17(8), 889-906.

Willett, W. C., Stampfer, M. J., Manson, J. E., Colditz, G. A., Speizer, F. E., Rosner, B. A., \& Sampson, L. A. (1993). Intake of trans fatty acids and risk of coronary heart disease among women. The Lancet, 341(8845), 581-585.

Zheng, X., \& Zhen, C. (2008). Healthy food, unhealthy food and obesity. Economics Letters, 100(2), 300-303.

\section{Publisher's Note}

Springer Nature remains neutral with regard to jurisdictional claims in published maps and institutional affiliations.

\section{Submit your manuscript to a SpringerOpen ${ }^{\circ}$ journal and benefit from:}

- Convenient online submission

- Rigorous peer review

- Open access: articles freely available online

High visibility within the field

- Retaining the copyright to your article

Submit your next manuscript at $\boldsymbol{\sim}$ springeropen.com 